MARSHALL, Pablo, "La privación de derecho a sufragio como castigo en la órbita del

common law: análisis crítico".

Polít. Crim. Vol. 14, № 28 (Diciembre 2019), Art. 15, pp. 520-561

[http://politcrim.com/wp-content/uploads/2019/12/Vol14N28A15.pdf]

\title{
La privación de derecho a sufragio como castigo en la órbita del common law: análisis crítico*
}

\section{Disenfranchisement as punishment within common law: critical analysis}

\author{
Dr. Pablo Marshall Barberán \\ Profesor de la Universidad Austral de Chile \\ pmarshall@uach.cl
}

\section{Resumen}

La privación del derecho a sufragio no puede ser justificada como un castigo democrático, dado que no puede superar las objeciones que se le plantean. Esto es así porque, primero, no puede explicarse en términos de incapacitación, rehabilitación o disuasión; y, segundo, cuando se argumenta que puede desempeñar una función retributiva, se llega a la conclusión de que no hay razones como para preferirla por sobre otras formas de castigo. El más sofisticado argumento para justificar la necesidad de la privación del derecho a sufragio en el contexto de sistemas jurídicos anglosajones, que lo vindica como una forma óptima de castigo expresivo, termina siendo poco convincente y contraproducente dentro de su propio marco conceptual. Hay buenas razones para pensar, por el contrario, que la privación del derecho a sufragio es una forma de castigo impermisible en una democracia, porque priva de un derecho que parece fundamental a la hora de imponer un castigo a aquellos que cometen un delito.

Palabras clave: derecho a sufragio, castigo penal, castigo expresivo, retribución

\begin{abstract}
.Disenfranchisement cannot be justified as a democratic punishment because it cannot overcome the objections that are raised. First, it cannot be explained in terms of incapacitation, rehabilitation or deterrence; and, second, when it is argued that disenfranchisement can perform a retributive function, there are no reasons to prefer it over other forms of punishment. The most sophisticated argument to justify the need for disenfranchisement in the context of common law jurisdictions, which defends it as an optimal form of expressive punishment, ends up being unconvincing and counterproductive within its own conceptual framework. There is good reason to think, contrast, that disenfranchisement is an impermissible form of punishment in a democracy, because it deprives a right that seems fundamental when what it is at stake is imposing a legitimate punishment on those who commit a crime.
\end{abstract}

Keywords: Right to vote, punishment, expressive punishment, retribution

\footnotetext{
${ }^{*}$ El presente trabajo fue desarrollado en el contexto de la investigación doctoral realizada por el autor en la Universidad de Glasgow.
} 


\section{Introducción}

Muchos sujetos que experimentan condenas penales alrededor del mundo no pueden votar en las elecciones porque han sido legalmente privados de su derecho a sufragio. Esta privación de su derecho a sufragio (en adelante PDS) se refiere a todos aquellos casos en los que un sujeto que ha sido criminalmente condenado es legalmente desposeído, temporal o permanentemente, de su derecho a sufragio. Esta definición asume que el condenado es idóneo para sufragar en razón de ciudadanía y edad electoral y que, por tanto, la condena criminal es la causa de su pérdida del derecho a sufragio. La mayoría de los países restringen esta medida a quienes están cumpliendo condenas privativas de libertad. Otros, suspenden el derecho a sufragio a grupos más amplios de sujetos sancionados. A veces, lo hacen incluyendo a todos los que han sido alguna vez condenados por un delito grave. ${ }^{1}$ Este tipo de práctica usualmente incluye la privación del derecho a presentarse como candidato en elecciones públicas y del derecho a ocupar cargos públicos, configurando así una constelación de exclusiones de la esfera pública. En otras palabras, se trata de una virtual cancelación de la ciudadanía democrática.

Como fruto de un análisis iniciado hace cuarenta años en EEUU, los círculos académicos del mundo anglosajón han estado cerca de alcanzar un consenso acerca de los efectos perniciosos de la PDS. Este consenso es tal, que algunos han sostenido que los críticos de "la pérdida de derecho a sufragio podrían sentirse un poco como un boxeador entrando en el ring sólo para notar que no existe oponente contra el que pelear". ${ }^{2}$ Variados argumentos han sido ofrecidos por parte de académicos de diversas disciplinas, tales como el derecho constitucional y el penal, la criminología, la sociología y la ciencia política. Entre ellos, pueden mencionarse que: (1) ha existido una confirmación de los efectos negativos de la PDS en el proceso de rehabilitación de los sujetos condenados; ${ }^{3}$ (2) los críticos han señalado el efecto degradante que conlleva la PDS, transformando a los sujetos condenados en ciudadanos de segunda clase; ${ }^{4}$ (3) la PDS es aplicada en términos en que produce un impacto discriminatorio a nivel social o racial; $;^{5}$ o (4) se ha dicho que los sujetos

\footnotetext{
1 Ver en general, MARSHALL, P., "Suspension of political rights of prisoners", en: GROTE; LACHENMANN; WOLFRUM (eds.), Max Planck Encyclopedia of Comparative Constitutional Law, Oxford: Oxford University Press, 2017. Ver también, ISPAHANI, L., "Voting rights and human rights: a comparative analysis of criminal disenfranchisement laws", en: EWALD, A.; ROTTINGHAUS, B. (eds), Criminal disenfranchisement in an international perspective, New York: CUP, 2009, pp. 25-58, passim.

${ }^{2}$ MANZA, J.; UGGEN, C., Locked out: Felon disenfranchisement and American democracy, New York: OUP, 2006, p. 12.

${ }^{3}$ Ver e.g. DEMLEITNER, N., "Continuing payment on one's debt to society: the German model of Felon disenfranchisement as an alternative", Minnesota Law Review, Vol. 84 (2000) 753-804, passim; DHAMI, M., "Prisoner disenfranchisement policy: a threat to democracy?", Analysis of Social Issues and Public Policy, Vol. 5, No 1 (2005), pp. 235-247.

${ }^{4}$ Ver e.g. FLETCHER, G. P., "Disenfranchisement as punishment: reflection on the racial uses of infamia", UCLA Law Review, Vol. 46 (1999), pp. 1895-1907, passim; BEHRENS, A., "Note: Voting- Not quite a fundamental right? A look at legal and legislative challenges to felon disenfranchisement laws", Minnesota Law Review, Vol. 89 (2004), pp. 231-275, passim; EASTON, S., "Electing the electorate: the problem of prisoner disenfranchisement”, Modern Law Review, Vol 69, № 3 (2006), pp. 443-461, passim.

5 Ver e.g. FLETCHER, "Disenfranchisement as punishment", cit. nota n 4; MAUER, M., "Felon disenfranchisement: a policy whose time has passed?”, Human Rights (American Bar Association), Vol. 31, $\mathrm{N}^{\mathrm{o}} 1$ (2004), pp. 16-17.
} 
condenados son expuestos a un trato injusto al impedirles expresar sus intereses en el proceso democrático. ${ }^{6}$

Impulsados por dicha reflexión académica, un grupo relativamente reciente de decisiones judiciales consideraron a la PDS como un problema significativo, y desde una perspectiva constitucional y de derechos humanos han efectuado un análisis crítico de esta institución. En diversas jurisdicciones del common law durante los últimos 20 años, se ha consolidado lo que podría llamarse una verdadera 'tendencia jurisprudencial', en que los tribunales han declarado la inconstitucionalidad o incompatibilidad de la legislación concerniente a la PDS, por considerar que esta constituye una violación del derecho a sufragio. ${ }^{7}$ Tribunales en otros países en África, Europa y Latinoamérica, incluido $\mathrm{Chile}^{8}$, no han estado ajenos a este proceso de análisis, aunque en menor medida.

Las razones ofrecidas por los gobiernos para defender la PDS han variado según los distintos contextos en los que se expresan. En los tribunales, cuando los gobiernos se han visto compelidos a explicar la racionalidad de la PDS, los argumentos han sido breves y consistentes. En ese contexto se esgrime que la PDS actúa como castigo adicional para los sujetos condenados, promoviendo la responsabilidad cívica y el respeto por el Estado de Derecho. ${ }^{9}$ Sin embargo, políticos que abordan el asunto en debates parlamentarios o en la prensa han estado menos contenidos, y los argumentos se han transformado en ocasiones en un ejercicio de slogans políticos. Así lo demuestra la declaración del ex Primer Ministro británico David Cameron, cuando el año 2010 afirmó lo siguiente: "Me da nauseas incluso contemplar la posibilidad de tener que dar voto a cualquiera que esté en la cárcel". ${ }^{10}$ Entre los demás argumentos entregados por políticos se encuentran algunos más intuitivos, tales como los que siguen: "cuando alguien quebranta el derecho, no puede participar en la

\footnotetext{
${ }^{6}$ Ver e.g. EASTON, "Electing the electorate", cit. nota ${ }^{\circ} 4$; DEMLEITNER, "Continuing payment", cit. nota $\mathrm{n}^{\circ} 3$; BEHRENS, "Note: Voting", cit. nota $\mathrm{n}^{\circ} 4$; DHAMI, "Prisoner disenfranchisement", cit. nota $\mathrm{n}^{\circ} 3$.

${ }^{7}$ Ver e.g. Chan Kin Sum v Secretary for Justice [2009] 2 HKLRD 166 and [2008] 6 HKC 486; Minister of Home Affairs $v$ National Institute for Crime Prevention and the Re-Integration of Offenders (NICRO) and Others (CCT 03/04) [2004] ZACC 10; Sauvé v Canada (Chief Electoral Officer), [2002] 3 S.C.R 519; Hirst v The United Kingdom (No. 2) [2005] ECHR 681; Roach v Commonwealth [2007] HCA 43; Scoppola v Italy (No. 3) [2012] ECHR 868.

${ }^{8}$ Sobre el caso chileno, ver MARSHALL, P., "El derecho a votar de los privados de libertad: propuestas para una reforma", en: CONTESSE, J.; CONTRERAS, L. (eds.), La insostenible situación de las cárceles en Chile: debate sobre la prisión y los Derechos Humanos, Santiago: Editorial Jurídica de Chile, 2019; MARSHALL, P.; ROCHOW, D., "El voto de las personas privadas de libertad. Comentario de la sentencia Rol N ${ }^{\circ} 87743-2016$ de la Corte Suprema”, Revista Chilena de Derecho Revista Chilena de Derecho, Vol. 45 , $\mathrm{N}^{\mathrm{o}} 1$, pp. 233-254, passim.

${ }^{9}$ Ver e.g. Hirst $v$ The United Kingdom (No. 2), cc. 74-5. Para una discusión detallada acerca de la justificación ofrecida en otros casos, ver e.g. PLAXTON, M.; LARDY, H. "Prisoner Disenfranchisement: Four Judicial Approaches", Berkeley Journal of International Law, Vol. 28, No 1 (2010), pp. 101-141, passim; ZIEGLER, R., "Legal outlier, again? U. S. felon suffrage: comparative and international human rights perspectives", Boston University International Law Journal, Vol. 29 (2011), pp. 197-266, passim.

${ }^{10}$ David Cameron, PM. Ver Hansard, HC Deb 517 col 921, 3 noviembre de 2010.
} 


\section{Polit. Crim. Vol. 15, № 28 (Diciembre 2019), Art. 15, pp. 520-561. [http://politcrim.com/wp-content/uploads/2019/12/Vol14N28A15.pdf]}

creación del derecho"; ${ }^{11}$ o bien, que si los "condenados son incapaces de dirigir sus propias vidas y no deberían tener permitido dirigir las nuestras". 12

En un intento de dar bases teóricas más sólidas a esta defensa de la PDS, algunas voces se han levantado desde dentro de la academia, en contra del consenso académico antes descrito y han aportado ideas importantes al debate. Aquellos que defienden cierta forma de la PDS han sostenido uno o más de los siguientes argumentos: (1) que la PDS es una expresión de voluntad democrática y debe ser respetada como tal; ${ }^{13}$ (2) que ella expresa la importancia de la autodeterminación del pueblo dentro de la democracia; ${ }^{14}$ (3) que establece un elemento de virtud cívica mínima como requisito de participación en las elecciones; ${ }^{15}$ y (4) que constituye una forma expresiva de castigo, en el contexto de la comisión de delitos graves o crímenes contra los valores democráticos. ${ }^{16}$ Este artículo está dedicado a analizar esta última propuesta en el ámbito del derecho constitucional, derecho penal y la teoría del castigo anglosajona.

Antes de avanzar debe considerarse, sin embargo, la razón por la cual la PDS debe analizarse en términos de un castigo penal. La frase "si quebrantas la ley, perderás el derecho a hacer la ley" ${ }^{\text {"17 }}$ se repite una y otra vez para expresar una de las intuiciones punitivas más persuasivas acerca de por qué los condenados deben perder su derecho a sufragio. Sin embargo, esta máxima es altamente indeterminada. En otra formulación, se

${ }^{11}$ David Davis, MP. Ver Hansard, HC Deb 523 col 493, 10 febrero 2011.

${ }^{12}$ Francis Marini, Massachusetts legislator, citado en EWALD, A., “An 'agenda for demolition': the fallacy and the danger of the 'subversive voting' argument for felony disenfranchisement", Columbia Human Rights Law Review, Vol. 36 (2004), p. 116.

${ }^{13}$ Ver ALTMAN, A., "Democratic Self-Determination and the Disenfranchisement of Felons", Journal of Applied Philosophy, Vol. 22, № 3 (2005), pp. 263-273; LATIMER, S. B., "Can felon disenfranchisement survive under modern conceptions of voting rights? Political philosophy, state interests, and scholarly scorn", SMU Law Review Vol. 59 (2006), pp. 1841-1867. Para una evaluación crítica, ver BÜLLOW, W., "Felon disenfranchisement and the argument for democratic self-determination”, Philosophia, Vol. 44 (2016), pp. 759-774; WHITT, M.S., Felon Disenfranchisement and Democratic Legitimacy, Social Theory and Practice, Vol. 43, pp. 283-311.

${ }^{14}$ Ver RAMSAY, P., "Faking democracy with prisoners' voting rights", LSE Law, Society and Economy Working Papers 7/2013, pp. 1-16, passim; RAMSAY, P., "Voters should not be in prison! The rights of prisoners in a democracy", Critical Review of International Social and Political Philosophy, Vol. 16, N 3 (2013), pp. 421-438, passim.

${ }^{15}$ Ver MANFREDI, C., "In Defence of Prisoner Disenfranchisement”, en: EWALD, A.; ROTTINGHAUS, B. (eds), Criminal disenfranchisement in an international perspective, New York: CUP, 2009, pp. 259-280, passim; CLEGG, R., "Who should vote?", Texas Review of Law and Politics, Vol. 6 (2002), pp. 159-178, passim; LATIMER, "Can felon", cit. nota $\mathrm{n}^{\circ}$ 13; SIGLER, M., "Defensible disenfranchisement", Iowa Law Review, Vol. 49 (2013), pp. 1725-1744, passim.Para una evaluación crítica, ver MARSHALL, P., "Disenfranchisement and political capacity", en: GRIFFITHS, A.; MUSTASAARI, S.; MÄKI-PETAJÄLEINONEN, A. (eds.), Subjectivity, Citizenship and Belonging in Law: Identities and Intersections, London: Routledge, 2016, pp. 53-71, passim.

${ }^{16}$ Ver HAMPTON, J., "Punishment, Feminism, and Political Identity: a case study in the expressive nature of law", Canadian Journal of Law and Jurisprudence Vol. 11, No 1 (1998), pp. 23-45, passim; LIPPKE, R., "The Disenfranchisement of Felons", Law and Philosophy, Vol. 20, No 6 (2001), pp. 553-580, p. 203; MANFREDI, "In Defence of", cit. nota $\mathrm{n}^{\circ} 15$, pp. 274-7; RE, R.; RE, C., "Voting and vice: criminal disenfranchisement and the reconstruction amendments", Yale Law Journal, Vol. 121 (2012), pp. 1584-1670, passim; BENNETT, C., "Penal disenfranchisement", Criminal law and philosophy, Vol. 10, № 3 (2016), pp. 411-425, passim.

${ }^{17}$ CHOLBI, M., “A felon's right to vote”, Law and Philosophy, Vol. 21, No 4/5 (2002), pp. 543-565, p. 550 
surgiere que "aquellos que son capaces de actuar en formas que privan a otros de la realización de los intereses defendidos a través de la participación política democrática, no pueden exigir, consistentemente, ejercer el derecho a sufragio" "; o "cuando los condenados exigen el derecho a sufragio, están reclamando el derecho a gobernar a otros, mientras rechazan el derecho de otros a gobernarlos a ellos". ${ }^{19}$ Estas declaraciones son fuertemente retóricas y, por ello mismo, es muy probable que altamente eficaces captando adhesión popular. Sin embargo, no explican completamente la relación entre el hecho de quebrantar la ley y despojar al condenado de su derecho a votar. Quienes proponen que la PDS es una consecuencia del quebrantamiento del contrato social se enfrentan a dificultades similares. ${ }^{20}$ La metáfora del contrato social puede contribuir a la justificación de varias instituciones como la democracia o el castigo. En todos estos casos, el contrato social puede tener algún rol que jugar. Sea cuales sean sus limitaciones, los argumentos contractualistas están profundamente conectados con otro tipo de justificación. Lo que se encuentra tras ellos es la creencia de que a la comisión de un delito debe seguirle una sanción, y que en aquellos casos en que se comete un delito penal, esta sanción tendrá la forma de un castigo. Sin embargo, los argumentos contractualistas no nos proveen de razón alguna que justifique porqué una sanción debe adoptar la forma de la PDS. $^{21}$ En una sociedad democrática, especialmente cuando este tipo de sanción involucra la limitación de un derecho fundamental, ellas deben adoptar la forma de castigos legalmente determinados y, por consiguiente, ser gobernadas por la lógica del derecho penal. ${ }^{22}$

\footnotetext{
${ }^{18}$ LIPPKE, "The Disenfranchisement of Felons", cit. nota ${ }^{\circ} 16$, p. 562.

${ }^{19}$ Silver citado en REIMAN, J., "Liberal and republican arguments against the disenfranchisement of felons", Criminal Justice Ethics, winter/spring 2005, pp. 3-18, p. 13. Ver también LIPPKE, “The Disenfranchisement of Felons", cit. nota n¹6, p. 561.

${ }^{20}$ Ver EWALD, A., "Civil Death: The Ideological Paradox of Criminal Disenfranchisement Law in the United States", Wisconsin Law Review, Vol. 5 (2002), pp. 1045-1137, pp. 1073-1079

${ }^{21}$ Ver REIMAN, "Liberal and republican", cit. nota $\mathrm{n}^{\circ} 19$. Respecto de argumentos contractualistas para la PDS con referencias a Locke, Hobbes y Rousseau, ver también PLANINC, Z., "Should imprisoned criminals have a constitutional right to vote?", Canadian Journal of Law and Society, Vol. 2 (1987), pp. 153-164, passim; NOTE, "The Disenfranchisement of ex-felons: citizenship, criminality, and 'the purity of the ballot box", Harvard Law Review, Vol. 102 (1989), pp. 1300-1317, pp. 1304-1307; LIPPKE, "The Disenfranchisement of Felons", cit. nota n 16, p. 561; EWALD, "Civil Death", cit. nota n 20, pp. 1072-9; JOHNSON-PARRIS, A. S., "Felon disenfranchisement: The unconscionable social contract breached", Virginia Law Review, Vol. 89, № 1 (2003), pp. 109-138, passim; BRENNER, S.; CASTE, N. J., "Granting the Suffrage to Felons in Prison", Journal of Social Philosophy, Vol. 34, No 2 (2003), pp. 228-243, pp. 238240; KLEINIG J.; MURTAGH, K., "Disenfranchising Felons", Journal of Applied Philosophy, Vol. 22 (2005), pp. 217-239, pp. 219-222; SCHALL, J., "The consistency of felon disenfranchisement with citizenship theory", Harvard Blackletter Law Journal, Vol. 22 (2006), pp. 53-93, pp. 68-83; EASTON, S., "The prisoner's right to vote and civic responsibility: Reaffirming the social contract?", Probation Journal, Vol. 56 (2009), pp. 224-237, p. 228; LEVINE, E. L., "Does the Social Contract Justify Felony Disenfranchisement?", Washington University Jurisprudence Review, Vol. 1 (2009), pp. 193-224, passim; BENNETT, "Penal disenfranchisement", cit. nota $\mathrm{n}^{\circ}$ 16, p. 4; PLAXTON; LARDY, "Prisoner Disenfranchisement", cit. nota ${ }^{\circ}$ 9, pp. 135-7; JOINT COMMITTEE ON DRAFT VOTING ELIGIBILITY (PRISONERS) BILL, Report (2013, HL 103, HC 924), pp. 34-36; BEHAN, C., "The benefit of personal experience and personal study: prisoners and the politics of enfranchisement", The Prison Journal, Vol. 91 (2011), pp. 9-10; LÓPEZ-GUERRA, C., Democracy and Disenfranchisement: The Morality of Electoral Exclusions, New York: OUP, 2014, pp. 110-2. Argumentos contractualistas también pueden ser encontrados en fallos judiciales. Ver e.g. Sauvé v Canada, cc. 31, 101-2; NICRO, c. 117.

${ }^{22}$ Ver BRENNER; CASTE, "Granting the Suffrage", cit. nota ${ }^{\circ} 21$, p. 231.
} 


\section{Polit. Crim. Vol. 15, № 28 (Diciembre 2019), Art. 15, pp. 520-561. [http://politcrim.com/wp-content/uploads/2019/12/Vol14N28A15.pdf]}

En un artículo anterior se analizó la idea de que la PDS está inspirada en la falta de ciertos elementos que hacen relación con la capacidad política de aquellos involucrados en un delito criminal. Esta idea fue criticada y descartada por ser incompatible con los principios democráticos que deben guiar la composición del padrón electoral. En una línea argumentativa que será continuada en este artículo, se sostuvo que una condena criminal debe ser considerada como una reafirmación de la capacidad del condenado para tomar decisiones autónomas. En otras palabras, ser capaz es un requisito para ser considerado responsable. Si la capacidad que se requiere para seguir reglas no es sustancialmente diferente a la capacidad para ser parte del proceso de producción de esas mismas reglas que es una idea democrática fundamental-, los sujetos condenados deben ser considerados como sujetos capaces para participar como electores. ${ }^{23}$

En este trabajo se analizará críticamente la tesis de que la PDS es una forma de castigo penal. Para ello se recurre a los numerosos trabajos académicos de la órbita del common law, asi como a los razonamientos de las principales sentencias de la anteriormente descrita 'tendencia transnacional', tanto de jurisdicciones del common law como de la Tribunal Europeo de Derechos Humanos El trabajo adoptará la siguiente estructura. La Sección I comienza haciendo una distinción conceptual y normativa entre el castigo y otras consecuencias de una condena criminal. En esta etapa, los fundamentos de protección social del castigo son rechazados como justificaciones satisfactorias de la PDS. En la Sección II, se analiza en detalle la idea de la PDS como una reacción retributiva ante la comisión de un delito. Este argumento se formula destacando que la PDS pueda servir como una forma expresiva del castigo democrático. Finalmente, la Sección III muestra que esta última justificación no satisface las condiciones para que el castigo sea compatible con un régimen democrático. Se argumenta que, incluso cuando la PDS pueda ser considerada, conceptualmente, como un castigo retributivo, es una modalidad del castigo que resulta incompatible con el reconocimiento de ciudadanos democráticos.

\section{Entendiendo la privación del sufragio como castigo}

\subsection{La naturaleza jurídica de la privación del sufragio}

Como se ha señalado anteriormente, la relación existente entre la PDS con la comisión de un delito criminal hace que tenga sentido considerarla como una forma de castigo. Así, por ejemplo, se ha entendido comúnmente PDS en Europa. Sin embargo, también hay una idea ampliamente extendida, con prevalencia especialmente en los Estados Unidos, que considera a la PDS como una consecuencia colateral de la condena. Esto significa que es un efecto legal que está conectado, pero al mismo tiempo separado del castigo en sí. En este último caso, el propósito de la PDS estaría en determinar el alcance del padrón electoral, más que castigar a los condenados por sus delitos. ${ }^{24}$

\footnotetext{
${ }^{23}$ Ver MARSHALL, "Disenfranchisement and political capacity", cit. nota $\mathrm{n}^{\circ} 15$.

${ }^{24}$ Ver e.g. DEMLEITNER, “Continuing payment”, cit. nota $\mathrm{n}^{\circ}$ 3, p. 753; EWALD, "Civil Death", cit. nota $\mathrm{n}^{\circ}$ 20, p. 1057; ISPAHANI, "Voting rights", cit. nota $\mathrm{n}^{\circ}$ 1, pp. 31-2; TRIPKOVIC, M., "The Modern Cives Sine Suffraggio: Dimensions of Criminal Disenfranchisement in Europe", The Howard Journal of Crime and Justice, Vol. 55 (2016), pp. 4-24
} 
La importancia de esta distinción trasciende lo retórico. Considerar a la PDS como un castigo, involucra asumir que esta debe ser diseñada y evaluada bajo una lógica punitiva, cuestión que involucra a su vez exigentes restricciones legales, constitucionales y teóricas. Por el otro lado, considerar a la PDS como una consecuencia colateral permite adoptar un enfoque mucho más flexible, ${ }^{25}$ en el cual la 'meta regulatoria' consistente en condicionar el derecho a sufragio y proteger el proceso electoral podría estar sujeta a estándares de control mucho menos estrictos que aquellos presentes en el sistema de garantías del derecho penal. ${ }^{26}$ Por ejemplo, una medida no punitiva no sería alcanzada por la protección del principio de irretroactividad de las leyes penales (ex post facto) ${ }^{27}$ o, como pasa en el derecho estadounidense, no sería examinada bajo el estándar de castigos 'crueles e inusuales" de la Octava Enmienda de la Constitución. ${ }^{28}$

Pese a que hablar acerca de las consecuencias colaterales de una condena criminal es especialmente confuso, cuando esta noción se examina más cuidadosamente, se pueden encontrar algunos criterios para entender esta distinción. Aparte de las insatisfactorias ideas que estipulan que las consecuencias colaterales son nombradas como tales en la legislación $^{29}$ y que no están bajo el control del juez, sino que son determinadas

${ }^{25}$ Ver VON HIRSCH, A., WASIK, M., "Civil disqualifications attending conviction: a suggested conceptual framework", Cambridge Law Journal, Vol. 56, № 3 (1997), pp. 599-626, pp. 611-615. Ver también SIGLER, "Defensible disenfranchisement", cit. nota $\mathrm{n}^{\circ} 15, \mathrm{pp} .22-3$.

${ }^{26}$ Ver EWALD, A., "Mundos aparte: las leyes sobre suspensión del derecho a sufragio en las Cortes Supremas", II Seminario Internacional del Observarotio Judicial Electoral, November 2009, Mexico, p. 12.

${ }^{27}$ Ver FEINBERG, J., "The expressive function of punishment", en: FEINBERG, J., Doing and Deserving. Princeton: Princeton University Press, 1970, pp. 95-117, pp. 106-109.

${ }^{28}$ Ver REBACK, G. L., "Disenfranchisement of Ex-Felons: A Reassessment", Stanford Law Review, Vol. 25, № 6 (1973), pp. 845-864, passim. Ver también NOTE, "The need of reform of ex-felons disenfranchisement laws", in Yale Law Journal, Vol. 83, No 3 (1974), pp. 580-601, pp. 598-599; TIMS, D., "The disenfranchisement of ex-felons: a cruelly excessive punishment", Southwestern University Law Review, Vol. 7 (1975), pp. 125-160, passim; FLETCHER, "Disenfranchisement as punishment", cit. nota $\mathrm{n}^{\circ}$ 4; THOMPSON, M., "Don't do the crime if you ever intend to vote again: challenging the disenfranchisement of ex-felons as cruel and unusual punishment", Seton Hall Law Review, Vol. 33 (2002), pp. 168-205, passim; KARLAN, P., "Ballots and bullets: the exceptional history of the right to vote", University of Cincinnati Law Review, Vol. 71 (2003), pp. 1345-1372; WILKINS, P. A., "The mark of Cain: disenfranchised felons and the constitutional no man's land", Syracuse Law Review, Vol. 56 (2005), pp. 85-144, passim; GRADY, S., "Civil death is different: and examination of a post-Graham challenge to felon disenfranchisement under the eighth amendment", The Journal of Criminal Law and Criminology, Vol. 102, № 2 (2012), pp. 441-470, pp. 441466.

${ }^{29}$ Esta idea sostiene que estas no deberían ser consideradas un tipo de castigo penal, en el sentido de ser una consecuencia directa de la condena, sino como un castigo regulatorio, o una consecuencia indirecta. Este punto de vista considera la condena como el hecho que active la aplicación de una norma regulatoria. Esta conceptualización, sin embargo, no ayuda mucho, considerando que el término 'colateral' reconoce que la imposición de un castigo penal también es una consecuencia, la consecuencia principal, de una condena criminal. El aspecto fundamental se convierte, entonces, en lo que cuenta como núcleo central y lo que cuenta como colateral. No hay un estándar operativo claro para juzgar esto más allá de una identificación legal. Este hecho se agrava por la terminología equívoca en la cual la regulación está expresada y por la ignorancia de las categorías doctrinarias en la actividad legislativa. Por ejemplo, Damaska es claro en rechazar la distinción entre castigo penal y otras consecuencias de una condena penal. Considera que los mismos efectos adversos de la condena se imponen bajo distintos rótulos, dependiendo de la decisión más o menos arbitraria del legislador (DAMASKA, M., "Adverse legal consequences of conviction and their removal: a comparative study (Part 1)", Journal of Criminal Law, Criminology and Police Science, Vol. 59, № 3 (1968), pp. 347-360, p. 349). La fuente legal sobre la cual se establece la medida puede ser relevante para, al menos 


\section{Polit. Crim. Vol. 15, № 28 (Diciembre 2019), Art. 15, pp. 520-561. [http://politcrim.com/wp-content/uploads/2019/12/Vol14N28A15.pdf]}

directamente por la ley, ${ }^{30}$ un tercer criterio pone atención al propósito o a la función que estas medidas buscan cumplir. Este criterio sugiere que una medida que es "apropiada para cumplir la función de reproche social" debe ser considerada como castigo. Por el otro lado, si no logra cumplir con aquel "simbolismo de reprobación", no puede ser considerada una medida punitiva, sino que meramente regulatoria. ${ }^{31}$ Por ejemplo, mientras que la privación de libertad es evidentemente punitiva, el registro de ofensores sexuales es esencialmente una medida preventiva y debe ser considerada, por lo tanto, como una consecuencia colateral. Esta diferencia funcional conlleva una propuesta que busca asimilar la consecuencia colateral con la amplia categoría de 'inhabilitaciones' para distinguirla de la noción de castigo. ${ }^{32}$

Desarrollando esta aproximación funcional, Andrew von Hirsch y Martin Wasik han sostenido que tanto las inhabilitaciones como el castigo deben ser claramente diferenciados, porque corresponden a dos funciones completamente diferentes. Esto es así, aunque ambas formalmente se sigan de una condena criminal. Por un lado, la inhabilitación corresponde a una medida que se hace cargo del riesgo y, por lo tanto, opera enfocada en conseguir disminuirlo. Por ejemplo, puede estar dirigida a evitar que un conductor, que ha sido demostrado que no respeta las reglas del tráfico, pueda conducir un vehículo motorizado. El castigo, por el otro lado, corresponde a una medida para expresar reproche o censura a una conducta criminal y, por lo tanto, opera retrospectivamente. ${ }^{33}$ Por ejemplo, está dirigida a expresar que matar a un peatón mientras se conduce a exceso de velocidad es incorrecto. Mientras que las inhabilitaciones no están sujetas a las mayores restricciones de derecho penal, no pueden, por otro lado, estar exentas de todo control racional, y deben en consecuencia estar sujetas a restricciones que hacen referencia a su propósito, duración y alcance. $^{34}$

superficialmente, la concepción que cada país tiene sobre la medida. Cuando esto se impone constitucionalmente, o se regula en leyes electorales, hay más probabilidades de que sea entendido como una consecuencia colateral. Cuando se establece en la legislación penal, hay más probabilidades de que sea entendido como un castigo penal.

${ }^{30}$ Cuando la corte tiene prerrogativas para imponer o limitar una medida con alguna medida de discreción, debe ser considerada como una consecuencia 'directa'. Por el otro lado, cuando una consecuencia no depende del tribunal, sino que está determinada legalmente, es 'colateral'. Al respecto, ver LOVE, M. C., "Collateral consequences after Padilla v Kentucky: from punishment to regulation”, Saint Louis University Public Law Review, Vol 31 (2011), pp. 87-128, pp. 95-97. Por ejemplo, una medida pública y declarada judicialmente puede ser vinculada con una racionalidad del castigo penal, mientras que el carácter implícito de una medida que no requiere de decisión judicial alguna y emana automáticamente de la condena, es más probable que sea considerada una consecuencia 'colateral'. Ver DEMLEITNER, N., "U. S. felon disenfranchisement: parting ways with western Europe”, en: EWALD A.; B. ROTTINGHAUS (eds.), Criminal disenfranchisement in an international perspective, Cambridge: Cambridge University Press, 2009, pp. 79-108, p. 82. Ver también ISPAHANI, "Voting rights", cit. nota $\mathrm{n}^{\circ} 1$, p. 31. Si bien este criterio estructural puede ser relevante para algunos aspectos legales, y puede incluso solucionar el debate respecto de la naturaleza 'colateral' de la PDS, evade la discusión sustantiva sobre si la PDS es o no un castigo penal.

${ }^{31}$ FEINBERG, "The expressive function of punishment", cit. nota $\mathrm{n}^{\circ} 27$, pp. 108-10.

${ }^{32}$ Ver ITZKOWITZ, H.; OLDAK, L., "Note: Restoring the ex-offender's right to vote: background and developments", American Criminal Law Review, Vol 11 (1973), pp. 729-30. Ver también LÓPEZ-GUERRA, Democracy and Disenfranchisement, cit. nota $\mathrm{n}^{\circ} 21$, pp. 130-2.

${ }^{33}$ Ver VON HIRSCH; WASIK, "Civil disqualifications", cit. nota n ${ }^{\circ} 25$, p. 601.

${ }^{34}$ Ver VON HIRSCH; WASIK, "Civil disqualifications”, cit. nota ${ }^{\circ} 25$, p. 605. 
Entender las medidas de inhabilitación como orientadas al riesgo conduce, necesariamente, a la formulación de una serie de restricciones para su uso. Primero, requieren una actividad específica o una ocupación a través de la cual, dicho riesgo se exprese; como sucede, por ejemplo, con actividades tales como conducir un automóvil. Segundo, requieren salvaguardar un interés o bien jurídico específico de aquel riesgo en particular (por ejemplo, los derechos del público que podría ser afectado con una conducción irresponsable). En concordancia con estas características, las inhabilitaciones deben ser determinadas en base a una predicción de las probabilidades reales de que el sujeto cometa un delito o produzca un daño. Sin embargo, para este propósito, las inhabilitaciones no deberían considerar las capacidades actuales del sujeto, sino la expectativa de futuras conductas en el campo de esas actividades. En estos términos, una regulación equilibrada de inhabilitaciones debería involucrar una relación proporcional entre la restricción a la autonomía de la persona y la evitación del riesgo. ${ }^{35}$

En contraste, el castigo expresa una censura a las conductas criminales pasadas de un sujeto, y por ello mismo, está gobernado por principios diferentes: el merecimiento y la proporcionalidad. De acuerdo a estas ideas, sólo aquellos que han sido declarados culpables de cometer un delito pueden ser castigados, y el castigo por su parte debe ser proporcional en su severidad a la gravedad de la conducta criminal. ${ }^{36}$ Sin embargo, en contraste a las inhabilidades, el castigo es normalmente considerado necesario incluso en la ausencia de algún riesgo de futuros delitos o daños. Esta descripción del propósito del castigo coincide con la idea de retribución, que es una de las funciones tradicionales del castigo. Sobre esa base, tanto riesgo prospectivo, como reproche retrospectivo, son las lógicas que gobiernan la aplicación de inhabilitaciones y castigos, respectivamente. ${ }^{37}$

Una virtud de este esquema que es clave para la tarea de este artículo, es que no sólo permite clasificar las consecuencias de una condena criminal en términos de inhabilitaciones y castigos, sino que también permite identificar aquellas medidas que no cumplen con ninguna de estas funciones. Demostrando su dimensión crítica, este esquema nos permite aplicar un escrutinio racional a la regulación legal en la medida que su uso indiscriminado puede conducir a tratar a los condenados como ciudadanos de segunda categoría. Por lo tanto, cuando una consecuencia no sigue los parámetros de culpabilidad y proporcionalidad, y por lo tanto no puede ser entendida como una medida conducente a reprochar, esta no podría ser considerada como un castigo. Por el otro lado, cuando una consecuencia no puede ser ligada a la prevención de un riesgo futuro, tampoco puede ser considerada como una inhabilitación. Lo que queda, según von Hirsch y Wasik, para aquellas medidas que no pueden ser justificadas existosamente como castigos o inhabilitaciones, es sólo el propósito de degradar a ciertos sujetos y ciertas actividades, lo que no debe quedar cubierto por el manto legitimador de un sistema jurídico-penal racionalizado. ${ }^{38}$

\footnotetext{
${ }^{35}$ Ver VON HIRSCH; WASIK, “Civil disqualifications”, cit. nota ${ }^{\circ} 25$, pp. 606-11.

${ }^{36}$ VON HIRSCH, A.; ASHWORTH, A., Principled Sentencing, Edinburgh: Edinburgh University Press, 1992, p. 182.

${ }^{37}$ Ver VON HIRSCH; WASIK, “Civil disqualifications”, cit. nota $\mathrm{n}^{\circ} 25$, pp. 615-20.

${ }^{38}$ Ver VON HIRSCH; WASIK, "Civil disqualifications", cit. nota ${ }^{\circ} 25$, p. 619. See also DAMASKA, "Adverse legal consequences of conviction", cit. nota n 29, p. 349
} 


\section{Polit. Crim. Vol. 15, № 28 (Diciembre 2019), Art. 15, pp. 520-561. [http://politcrim.com/wp-content/uploads/2019/12/Vol14N28A15.pdf]}

\subsection{Incapacitación y protección social}

\subsubsection{Incapacitación criminal}

Como se mencionara en la introducción, la idea de que la PDS puede operar como una medida de incapacitación electoral ya ha sido considerada en un trabajo anterior. ${ }^{39}$ En aquella ocasión, sin embargo, la incapacitación fue entendida como una medida no basada en el riesgo de la comisión de un delito penal, sino como la protección de las elecciones de la influencia de aquellos que carecen de la virtud cívica necesaria para participar en ellas. De allí la distinción entre 'incapacitación electoral' e 'incapacitación criminal'.

Aquí toca analizar si la PDS puede servir específicamente como incapacitación criminal. La incapacitación criminal es usualmente considerada como uno de los propósitos del castigo. De acuerdo a este punto de vista, el castigo funciona cuando impide directamente la comisión de nuevos delitos por parte del sujeto condenado ${ }^{40}$ y está basado en la predicción de las probabilidades de que el condenado reincida. Sin embargo, en el esquema funcional presentado anteriormente, la incapacitación o inhabilitación se distingue del castigo como una medida diferente, gobernada por otros principios y orientada a la prevención de delitos futuros.

Considerado en estos términos, el potencial de incapacitación de la PDS es probablemente muy débil, dado que tendría poco impacto en la prevención de nuevos delitos. Su potencial para producir incapacitación criminal general (la capacidad para prevenir cualquier tipo de delitos) es considerablemente estrecha, porque no podría razonablemente servir para prevenir la comisión de otros delitos aparte de las ofensas electorales, a diferencia de lo que sucede, por ejemplo, con la privación de libertad, que por el contrario tiene un alto potencial de incapacitación general. ${ }^{41}$ Por otro lado, es difícil juzgar el aspecto incapacitante de la PDS en relación con la comisión de delitos electorales. Para este propósito, el efecto de la PDS debe ser cuidadosamente diferenciado del efecto de la privación de libertad, cuando estas dos medidas se superponen en el tiempo. Los reos, así, no pueden cometer crímenes electorales si el proceso electoral sólo existe afuera de la cárcel. Sin embargo, como resulta evidente, este sería un efecto de la privación de libertad y no de la PDS.

En una primera hipótesis, la PDS podría tener el efecto de prevenir fraudes electorales dentro de la cárcel. Sin embargo, ningún estudio empírico ha revelado que los privados de libertad sean más o menos proclives que el resto de la ciudadanía a cometer fraudes electorales u otros delitos electorales. ${ }^{42}$ Aquellos que cometen fraudes electorales no son usualmente condenados por otros tipos de delitos, porque la racionalidad tras la criminalidad electoral es diferente a otros tipos de criminalidad. Es más, es extraño que aquellos condenados por delitos electorales sean encarcelados, dado que este tipo de

\footnotetext{
${ }^{39}$ MARSHALL, "Disenfranchisement and political capacity", cit. nota ${ }^{\circ} 15$.

${ }^{40}$ Ver FLETCHER, G. P., Basic concepts of criminal law. New York: OUP, 1998, p. 31.

${ }^{41}$ Ver REIMAN, "Liberal and republican", cit. nota n ${ }^{\circ} 19$, p. 9. Ver también MANZA; UGGEN, Locked out, cit. nota ${ }^{\circ} 2$, p. 36 .

${ }^{42}$ Ver NOTE. "The Disenfranchisement of ex-felons", cit. nota ${ }^{\circ}$ 21, p. 1303. Ver también EWALD, "Civil Death", cit. nota n 20, pp. 1088-9; MANZA; UGGEN, Locked out, cit. nota n² 2, p. 13.
} 
criminalidad, al igual que la criminalidad de cuello blanco, debiera tender a ser calificada como una criminalidad poco peligrosa. Cuando estos elementos son considerados, aparece como evidente que el costo de mantener distanciados a los condenados por delitos electorales de las urnas es muy alto si sólo se consigue a través de la exclusión de todos los reos. Incluso es posible afirmar que es una medida inidónea para lograr dicho objetivo. En conclusión, cuando esta prohibición afecta a todos los condenados, es evidentemente súperinclusiva. ${ }^{43}$ Asimismo, se ha argumentado que el control social ejercido en el ambiente de la cárcel, es razón suficiente controlar el proceso electoral dentro de las cárceles y debe ser suficiente para superar el riesgo de la comisión de fraudes electorales, u otros delitos relacionados. 44

En una segunda hipótesis, cuando afecta a quienes ya sirvieron su condena privativa de libertad, la PDS tiene más probabilidades de cumplir su propósito de prevenir fraudes electorales. ${ }^{45}$ No obstante, el alcance de este argumento es también limitado. Tampoco hay una conexión racional entre la PDS y la prevención de fraude electoral, porque la comisión de este último no requiere necesariamente que el involucrado sea titular habilitado del derecho de sufragio. ${ }^{46}$ Sin embargo, aquí se pueden hacer varias distinciones relevantes. Algunos delitos electorales requieren que el criminal sea un votante calificado (por ejemplo, como sucede con quien vende su voto), mientras otros no lo requieren (por ejemplo, como sucede con el soborno). Por esto, podría justificarse, bajo la lógica de la incapacitación, el despojar a una persona que ha sido condenada repetidamente por vender su voto, de su derecho a sufragar para así impedir que lo venda nuevamente. ${ }^{47}$ Pero como ya se ha mencionado, esta sería un caso calificado y, valga destacar, bastante raro, especialmente considerando que la mayoría de las legislaciones consideran los delitos electorales no suficientemente graves para gatillar la aplicación de la PDS. ${ }^{48}$

\footnotetext{
${ }^{43}$ Ver Richardson v Ramirez, 418 U.S. 24 (1974), esp. voto disidente, c. 79. Ver también VILE, J., "Right to Vote as Applied to Ex-Felons", Federal Probation, Vol. 45 (1981), pp. 12-17; BENNETT, S., "Giving ExFelons the Right to Vote", California Criminal Law Review, Vol. 1 (2003), par. 19; KLEINIG; MURTAGH, "Disenfranchising Felons", cit. nota n²1, p. 227; MANZA; UGGEN, Locked out, cit. nota n², p. 13.

${ }^{44}$ Ver EASTON, "The prisoner's right to vote and civic responsibility", cit. nota $\mathrm{n}^{\circ} 21$, p. 230. En contra de esta opinión se ha argumentado el ejercicio del sufragio en las condiciones carcelarias en que viven los privados de libertad, típicamente condiciones de sujeción frente a la autoridad ejecutiva (o a las mafias carcelarias) es justamente la razón que pone en riesgo la integridad de la elección en la medida que pueden ser blanco de coacción y manipulación (ver RAMSAY, "Faking democracy", cit. nota n 14; RAMSAY, "Voters should not be in prison", cit. nota $n^{\circ} 14$; LÓPEZ-GUERRA, Democracy and Disenfranchisement, cit. nota 21, pp. 118-124). En un artículo anterior en que se ha abordado esta crítica, se ha sostenido, primero, que los privados de libertad no pueden ser hechos responsables de las condiciones de su encarcelamiento y que las cárceles deben cumplir ciertos requisitos democráticos; y, segundo, que esta crítica menosprecia la capacidad de la reforma penitenciaria para superar los problemas de coacción y manipulación electoral (ver MARSHALL, P., "Voting from prison: against the democratic case for disenfranchisement", Ethics and Global Politics, Vol. 11 (2018), p. 1-16.

${ }^{45}$ Ver BENNETT, "Giving Ex-Felons", cit. nota ${ }^{\circ} 43$, par. 18.

${ }^{46}$ Ver MANZA; UGGEN, Locked out, cit. nota $n^{\circ} 2$, p. 36.

${ }^{47}$ Ver LÓPEZ-GUERRA, Democracy and Disenfranchisement, cit. nota $\mathrm{n}^{\circ} 21$, p. 115.

${ }^{48}$ Ver LARDY, H., "Prisoner disenfranchisement: constitutional rights and wrongs", Public Law, (2002), pp. 525-545, p. 526. Ver también NOTE. “The Disenfranchisement of ex-felons", cit. nota n” 21, p. 1303; KLEINIG; MURTAGH, "Disenfranchising Felons", cit. nota ${ }^{\circ}$ 21, p. 220.
} 


\section{Polit. Crim. Vol. 15, № 28 (Diciembre 2019), Art. 15, pp. 520-561. [http://politcrim.com/wp-content/uploads/2019/12/Vol14N28A15.pdf]}

Como puede concluirse, es difícil defender la idea de que la PDS puede incapacitar a los condenados para cometer cualquier tipo de crimen a futuro, tal vez con la única excepción de la venta de votos. ${ }^{49}$ Por eso es tiempo de examinar el potencial punitivo de esta medida. El hecho de que la PDS sea la consecuencia de una condena criminal, y que esté orientada retrospectivamente, podría ser un indicador de su naturaleza punitiva. Tradicionalmente, los propósitos del castigo están clasificados en tres categorías: prevención, rehabilitación y retribución. Las primeras dos funciones están guiadas por el propósito general de protección social, mientras que la retribución está inspirada por la meta normativa abstracta de que los condenados deben recibir el castigo que se merecen de acuerdo a sus acciones. Sin embargo, en el esquema funcional, prevención y rehabilitación deben ser consideradas junto con la incapacitación como preventivas en lugar de punitivas. Estos aspectos del castigo no están orientados retrospectivamente, sino que miran a prevenir la comisión de nuevos delitos, y como tales no pueden calificarse como punitivos. Como mucho, podrían servir a modo de una meta colateral de la ejecución del castigo (por ejemplo, la rehabilitación), o como una justificación del sistema criminal global (por ejemplo, la prevención). La siguiente exposición, sin embargo, no busca cuestionar teóricamente el propósito generalmente aceptado y las funciones sociales del castigo, sino analizar la PDS desde el punto de vista de las versiones estandarizadas de las mismas. ${ }^{50}$

\subsubsection{Disuasión}

El propósito de la disuasión tiene dos aspectos, uno general y uno especial. La disuasión general está basada en la predicción de que castigar a un criminal influenciará a otros a no cometer el mismo delito. La disuasión especial busca evitar que el condenado cometa futuros delitos después de cumplir su condena.

La idea básica de este enfoque es que las personas sean disuadidas de cometer un delito, debido al temor provocado por la penalidad que arriesgan. Es difícil separar la dimensión negativa, de la dimensión positiva del castigo preventivo, expresada como una búsqueda de educación moral, reinserción social y reforzamiento del respeto por el derecho. Estos últimos aspectos juegan un rol fundamental en los intentos por caracterizar la PDS como una forma adecuada de castigo, siendo invocados frecuentemente por el gobierno y las cortes constitucionales en casos donde la PDS ha sido discutida. ${ }^{51}$

Por un lado, el potencial de la PDS depende de cuánta importancia den las personas al derecho a sufragio, de manera que sean efectivamente disuadidos de cometer delitos por el miedo a perder este derecho. Además, la disuasión requiere que el sujeto tenga conocimiento del tipo de medida que se le impone, si esperamos que esto influencie su

\footnotetext{
${ }^{49}$ Otras conceptualizaciones de la inhabilitación pueden ser aún más restrictivas y dirigidas directamente a impedir la comisión del mismo tipo de delito por el cual se impuso la condena (en este caso, un delito electoral). Este es un punto de vista interesante desde el cual evaluar la PDS cuando se observa que algunos de los delitos electorales no necesariamente incurren en esta medida. Ver VON HIRSCH; WASIK, "Civil disqualifications", cit. nota ${ }^{\circ} 25$, p. 606; DEMLEITNER, "Continuing payment", cit. nota $\mathrm{n}^{\circ} 3$, pp. 7923.

${ }^{50}$ Para una discusión de estos objetivos, ver VON HIRSCH; ASHWORTH, Principled Sentencing, cit. nota $\mathrm{n}^{\circ} 36$.

${ }^{51}$ Vér e.g. Hirst v the United Kingdom (No 2), c. 50, Sauvé v Canada, c. 21, NICRO, c. 139.
} 
conducta. ${ }^{52}$ En este sentido, el efecto disuasivo de la PDS requeriría su imposición pública, y no como sucede con la mayoría de los casos en el derecho comparado, de forma silenciosa ${ }^{53}$. Incluso en ese caso, el efecto físicamente imperceptible de la PDS podría limitar su potencial disuasivo. ${ }^{54}$

Por otro lado, la función disuasiva de la PDS es un asunto difícil de demostrar. La base de la lógica disuasiva descansa sobre la suposición de que es posible motivar la conducta de una persona. Aparte de los problemas empíricos generales que complican la exploración de la disuasión penal en general, es difícil imaginar un caso en que una persona sea efectivamente disuadida de cometer un crimen, basado en el castigo adicional que la PDS supondría. Es más prometedor pensar que, como un agente racional, la persona ya ha sido disuadida por el temor a una medida punitiva mucho más severa como es la privación de libertad. ${ }^{55}$ Esta posición está apoyada por estudios empíricos llevados a cabo en los Estados Unidos, que confirman nuestro escepticismo en lo que concierne la disuasión. Primero, estos estudios han confirmado la ignorancia pública y ampliamente extendida en relación a la existencia de la PDS, y que esta ignorancia incluso se extiende a profesionales de la justicia, incluyendo jueces y abogados penalistas. ${ }^{56}$ Segundo, los estudios han demostrado que muchos condenados no son disuadidos de cometer crímenes por el castigo de privación de libertad, sino que usualmente son más influenciados por factores situacionales. ${ }^{57}$ Tercero, a un nivel personal, los condenados tienden a valorar otras cosas por sobre los derechos políticos que podrían llegar a perder. ${ }^{58} \mathrm{Si}$ todo esto resulta cierto, es difícil sostener que agregar la PDS a la privación de libertad podría evitar la comisión de más delitos. ${ }^{59}$ Esta evidencia demuestra, las sospechas de que la disuasión parece no funcionar en relación a la PDS.

\subsubsection{Rehabilitación y reinserción}

La otra función del castigo orientada a la protección social es la rehabilitación. Consiste en una interpretación terapéutica del castigo, que trata a los condenados como 'pacientes' y, por lo tanto, conduce a la cura o al cambio de sus supuestas tendencias criminales. $\mathrm{Su}$

\footnotetext{
${ }^{52}$ Ver Sauvé v Canada, voto disidente, cc. 119-21; NICRO, voto disidente, c. 116.

${ }^{53}$ Ver EWALD, "Civil Death", cit. nota n 20, pp. 1117-9.

${ }^{54}$ Ver DEMLEITNER, “Continuing payment”, cit. nota ${ }^{\circ} 3$, p. 788. Ver también CHOLBI, “A felon’s right to vote", cit. nota 17, p. 557; HILL, L.; KOCH, C., "The voting rights of incarcerated Australian citizens", Australian Journal of Political Science, Vol. 46, No 2 (2011), pp. 213-228, p. 224.

${ }^{55}$ Ver ITZKOWITZ; OLDAK, "Note: Restoring the ex-offender's", cit. nota $\mathrm{n}^{\circ} 32$, pp. 734-9. Ver también TIMS, "The disenfranchisement of ex-felons", cit. nota $n^{\circ} 28$, p. 157; NOTE. "The Disenfranchisement of exfelons", cit. nota $n^{\circ}$ 21, p. 1303; EWALD, "Civil Death", cit. nota n ${ }^{\circ}$ 20, p. 1106; BENNETT, "Giving ExFelons", cit. nota ${ }^{\circ}$ 43, par. 20, 33-5; BRENNER; CASTE, "Granting the Suffrage”, cit. nota n 21, p. 233; REIMAN, "Liberal and republican", cit. nota $\mathrm{n}^{\circ}$ 19, p. 9; MANZA; UGGEN, Locked out, cit. nota $\mathrm{n}^{\circ} 2$, p. 36; EASTON, "Electing the electorate", cit. nota $n^{\circ} 4$, p. 450; LEVINE, "Does the Social Contract", cit. nota $\mathrm{n}^{\circ} 21$, pp. 220-1.

${ }^{56}$ Ver MANZA; UGGEN, Locked out, cit. nota ${ }^{\circ}$ 2, p. 36. Ver también EASTON, “The prisoner's right to vote and civic responsibility", cit. nota ${ }^{\circ} 21$, pp. 229-30.

${ }^{57}$ Ver VON HIRSCH; ASHWORTH, Principled Sentencing, cit. nota $\mathrm{n}^{\circ}$ 36, p. 57.

${ }^{58}$ Ver e.g. JOINT COMMITTEE ON DRAFT VOTING ELIGIBILITY (PRISONERS) BILL, Report (2013, HL 103, HC 924), p. 40.

${ }^{59}$ Ver CHOLBI, “A felon's right to vote”, cit. nota ${ }^{\circ} 17$, pp. 557-558.
} 


\section{Polit. Crim. Vol. 15, № 28 (Diciembre 2019), Art. 15, pp. 520-561. [http://politcrim.com/wp-content/uploads/2019/12/Vol14N28A15.pdf]}

resultado esperado es prevenir futuros delitos por parte de los condenados rehabilitados. La terminología moderna ha evolucionado desde la noción de rehabilitación al lenguaje de la reinserción, debido a los problemas éticos que se derivan del primero, como la necesidad de limitar las acciones estatales y la falta de respeto que implica hacia la persona del condenado. ${ }^{60}$ En el nuevo paradigma, el énfasis ya no se pone en cambiar la personalidad del condenado, sino en mejorar su habilidad para funcionar normalmente en la sociedad. ${ }^{61}$

De esta manera, la PDS, como medida de rehabilitación o reinserción social, puede jugar un rol importante para transformar a los condenados en ciudadanos que respeten las leyes. Concebir la devolución del derecho a sufragio como un premio, es sostenido, podría motivar la buena conducta de los condenados, promoviendo la reinserción, destacando los derechos y responsabilidades de la ciudadanía. ${ }^{62}$ Sin embargo, este potencial resultado se verá frustrado si la PDS continúa por mucho tiempo luego de que el condenado quede en libertad, o si el proceso de devolución del derecho a sufragio es muy difícil de lograr o implica un procedimiento demasiado complicado. ${ }^{63}$ De hecho, una PDS permanente o de duración excesiva es irreconciliable con un propósito de reinserción social, y tiene más probabilidades de excluir y estigmatizar a los condenados. ${ }^{64}$ Es por esto que la función de rehabilitación sólo puede operar cuando la devolución del derecho a sufragio sea inmediatamente después de que el sujeto quede en libertad. ${ }^{65}$

Sin embargo, incluso en la hipótesis menos restrictiva puede objetarse que la PDS es incompatible con el compromiso re-educativo de las teorías de rehabilitación. La estigmatización y degradación que es inmanente a la PDS no pueden contribuir a estos propósitos. Esta ha sido la opinión de la Corte Suprema Canadiense en Sauvé v Canada, al afirmar que el intento de enviar un 'mensaje educativo' cuando se despoja a los condenados de su derecho a votar es una 'mala pedagogía' 66 y que la PDS implica "perder un medio importante de enseñarles valores democráticos y responsabilidad social" a los condenados. ${ }^{67}$ La evidencia empírica en los Estados Unidos también se dirige en aquella dirección: "para un número importante de ex presidiarios, la pérdida del derecho de sufragio supone un obstáculo en el éxito de su reinserción". ${ }^{68}$ Incluso, ésta puede llegar a

\footnotetext{
${ }^{60}$ Ver VON HIRSCH; ASHWORTH, Principled Sentencing, cit. nota $\mathrm{n}^{\circ} 36, \mathrm{p} .3$.

${ }^{61}$ Ver VAN ZYL SMIT, D.; SNACKEN, S., Principles of European Prison Law and Policy, Oxford: OUP, 2009 , p. 83.

${ }^{62}$ SIGLER, "Defensible disenfranchisement", cit. nota $\mathrm{n}^{\circ} 15$, pp. 18-9.

${ }^{63}$ Ver MANZA; UGGEN, Locked out, cit. nota $\mathrm{n}^{\circ}$ 2, p. 37. Ver también LEVINE, "Does the Social Contract", cit. nota ${ }^{\circ} 21$, p. 223.

${ }^{64}$ Ver DEMLEITNER, "Continuing payment", cit. nota ${ }^{\circ} 3$, pp. 775, 785-6.

${ }^{65}$ Ver DEMLEITNER, “U. S. felon disenfranchisement”, cit. nota $\mathrm{n}^{\circ}$ 30, p. 101.

${ }^{66}$ Sauvé v Canada, c. 30.

${ }^{67}$ Sauvé v Canada, c. 38.

${ }^{68}$ MILLER, B. L.; SPILLANE, J., "Civil death: an examination of ex-felon disenfranchisement and reintegration", Punishment \& Society Vol. 14, No 4 (2012), pp. 402-428, p. 402. Ver también las partes intervinientes en Hirst $v$ The United Kingdom (No. 2), c. 53. Hamilton-Smith y Vogel demuestran la conexión entre la PDS y la reincidencia (Ver HAMILTON-SMITH, G.; VOGEL, M., "The ballot as a bulwark: the impact of felony disenfranchisement on recidivism”, 2011. Available online: http://ssrn.com/abstract=1919617 [20.10.2014]). Ver también el análisis inconcluso de MANZA; UGGEN, Locked out, cit. nota $\mathrm{n}^{\circ} 2$, pp. 124-135.
} 
afectar a la comunidad en general a la que pertenecen aquellos que han sido despojados del derecho en cuestión. ${ }^{69}$

En contraste, estrategias de rehabilitación que sean inclusivas y participativas pueden generar la deseada conciencia respecto a la importancia de la participación política, del respeto al derecho y al valor de la vida en comunidad. Dejar que los condenados voten, podría contribuir a la construcción de un sentimiento de pertenencia a la comunidad e incluso contribuir a la transformación de 'identidades criminales'. ${ }^{70}$ Yendo más lejos, desde el punto de vista de un ideal rehabilitador, sería más razonable estimular a los condenados a participar en las elecciones ${ }^{71}$, e incluso imponerles el voto obligatorio ${ }^{72}$, en lugar de excluirlos del mismo. Esto podría significar un método más efectivo y coherente para desafiar conductas e identidades desviadas. ${ }^{73}$

\section{Privar del sufragio como castigo}

Las funciones sociales del castigo asociada a la prevención, la rehabilitación y la incapacitación depende en gran medida de la satisfacción de su propósito. Ya ha sido visto cómo, incluso independiente de demostraciones empíricas, estas funciones parecen inadecuadas para justificar la medida de la PDS. El éxito de la retribución, en contraste, no depende de la verificación empírica de dicho propósito, sino en una configuración adecuada de la estructura legal para para que ésta calce con una reacción punitiva retrospectiva. Sin embargo, la explicación retributiva de la PDS se enfrenta a otro tipo de problemas. Esta sección examina cómo la teoría retributiva del castigo puede ser aplicada a la PDS en particular, presentando una concepción de la PDS que podría explicar por qué es una forma de castigo admisible y adecuada.

\subsection{Privar del sufragio como un castigo retributivo}

\footnotetext{
${ }^{69}$ Ver BOWERS, M.; PREUHS, R., "Collateral consequences of a collateral penalty: the negative effect of felon disenfranchisement laws on the political participation of nonfelons", Social Science Quarterly, Vol. 90, No 3 (2009), pp. 722-743, passim

${ }^{70}$ Ver MANZA; UGGEN, Locked out, cit. nota $\mathrm{n}^{\circ}$ 2, Cap. 6. Ver también ITZKOWITZ; OLDAK, "Note: Restoring the ex-offender's", cit. nota ${ }^{\circ}$ 32, p. 732; TIMS, "The disenfranchisement of ex-felons", cit. nota 28, p. 156; CHOLBI, “A felon's right to vote", cit. nota $\mathrm{n}^{\circ}$ 17, pp. 558-9; BENNETT, "Giving Ex-Felons", cit. nota 43, par. 43-5; KLEINIG; MURTAGH, "Disenfranchising Felons”, cit. nota 21, pp. 229-30; REIMAN, "Liberal and republican", cit. nota $\mathrm{n}^{\circ}$ 19, pp. 9 y 13-4; JOINT COMMITTEE ON DRAFT VOTING ELIGIBILITY (PRISONERS) BILL, Report (2013, HL 103, HC 924), pp. 41-2. Ver también las partes intervinientes (c. 54) y la opinión concurrente del Juez Caflisch (c. 5) en Hirst v The United Kingdom (No. 2).

${ }^{71}$ Ver DEMLEITNER, “U. S. felon disenfranchisement”, cit. nota $\mathrm{n}^{\circ}$ 30, p. 94. Ver también BEHAN, C., Citizen Convicts: Prisoners, Politics and the Vote, Manchester: Manchester University Press, 2014, Cap. 7.

${ }^{72}$ Ver la propuesta de POAMA, A.; THEUS, T., "Making offenders vote: democratic expressivism and coerced criminal voting", presentación en Seminario The Politic and Ethics of Disenfranchisement, Universidad de Manchester, 2017.

${ }^{73}$ Ver EWALD, "Civil Death", cit. nota n² 20, pp. 1110-1. Ver también BRENNER; CASTE, "Granting the Suffrage”, cit. nota $n^{\circ} 21$, p. 232; MANZA; UGGEN, Locked out, cit. nota $n^{\circ}$ 2, p. 37. Ver, críticamente RAMSAY, quien argumenta que utilizar la PDS como herramienta de rehabilitación es transformar el voto (un derecho político) en un derecho social, y el valor de la auto-determinación es reducido a un mero fin político ("Voters should not be in prison", cit. nota n' 14, pp. 424, 430-1).
} 


\section{Polit. Crim. Vol. 15, № 28 (Diciembre 2019), Art. 15, pp. 520-561. [http://politcrim.com/wp-content/uploads/2019/12/Vol14N28A15.pdf]}

Ya se mencionó que el castigo corresponde a una medida apta para expresar reproche frente a una conducta criminal. Esto corresponde en gran medida a la idea de la retribución. En contraste a la disuasión y la rehabilitación, la retribución se caracteriza comúnmente tanto por su justificación puramente abstracta, y por tanto no necesitar prueba empírica alguna, como también por su orientación retrospectiva. La principal exigencia del castigo retributivo, y lo que asegura su popularidad en tiempos actuales, es que el condenado es tratado como un agente moral autónomo. Esto se alcanza estableciendo limitaciones racionales al ius puniendi estatal. Primero, el castigo debe ser y sólo puede ser impuesto sobre aquellos que han sido condenados como culpables de la comisión de un delito. Segundo, la relación entre el quantum del castigo y la gravedad del delito debe ser proporcional. $^{74}$ Un castigo retributivo no es necesariamente incompatible con otros propósitos como la disuasión o la rehabilitación; sin embargo, estas nociones juegan roles secundarios en este esquema gobernado por la lógica del merecimiento. ${ }^{75}$

Entender que la PDS puede funcionar como un castigo para aquellos que han cometido un delito no presenta un problema de demostración empírica, dado que, si está justificado el imponer una sanción al condenado, y esta sanción es adecuada para manifestar un reproche, entonces la medida será perfectamente retributiva. El hecho de que los condenados no valoren su derecho a sufragio, o al menos, no lo valoren tanto como lo hacen con otros derechos, no constituye una objeción al potencial punitivo de la PDS. ${ }^{76}$ Es razonable que los condenados estén más preocupados de "conseguir una casa decente o un trabajo [...] que de tener el derecho a votar". ${ }^{77}$ La dimensión retributiva de una medida, sin embargo, no depende de apreciaciones subjetivas sino que depende del hecho de que una persona está siendo efectivamente privada de un derecho fundamental como consecuencia de una condena criminal. Como ha señalado la Corte Suprema de Canadá en este mismo sentido, cuando "se niegan derechos políticos básicos, no se requiere prueba de daños adicionales". 78

La crítica más común que afecta a la PDS no tiene relación con su desempeño retributivo, sino con la escasez de proporcionalidad entre la naturaleza y gravedad del delito, y la forma y el quantum del castigo. ${ }^{79}$ Sin embargo, si bien esto puede ser verdadero en algunos casos, no parece afectar a la PDS de forma generalizada. El caso más claro de un problema de proporcionalidad ocurre cuando la PDS ha sido impuesta permanentemente, o bien continúa afectando a los sujetos involucrados incluso después de concluir sus penas privativas de libertad. ${ }^{80}$ En estos casos, la ausencia de proporcionalidad se evidencia por su contraste con la efectiva proporcionalidad de la privación de libertad. Si la privación de

\footnotetext{
${ }^{74}$ Ver VON HIRSCH; ASHWORTH, Principled Sentencing, cit. nota n ${ }^{\circ} 36, \mathrm{p} .181$.

${ }^{75}$ Ver VON HIRSCH; ASHWORTH, Principled Sentencing, cit. nota ${ }^{\circ} 36$, p. 182.

${ }^{76}$ Ver JOINT COMMITTEE ON DRAFT VOTING ELIGIBILITY (PRISONERS) BILL, Report (2013, HL 103, HC 924), p. 40. Ver también DEMLEITNER, “U. S. felon disenfranchisement”, cit. nota n 30, p. 94.

${ }^{77}$ LACEY, N., "Oral Evidence", en: Joint Committee on the draft Voting Eligibility (Prisoners) Bill Oral and Written Evidence, 2013, p. 107.

${ }^{78}$ Sauvé v Canada, c. 59.

${ }^{79}$ EASTON, "The prisoner's right to vote and civic responsibility", cit. nota $n^{\circ} 21$, p. 229.

${ }^{80}$ Ver FLETCHER, "Disenfranchisement as punishment", cit. nota ${ }^{\circ} 4$, p. 1896. Ver también EWALD, "Civil Death", cit. nota $n^{\circ}$ 20, p. 1103; SCHALL, "The consistency of felon disenfranchisement", cit. nota $\mathrm{n}^{\circ}$ 21, p. 75.
} 
libertad, generalmente considerada como un castigo serio, es impuesta por un tiempo limitado, en relación proporcional a la gravedad del delito, la PDS debe también seguir esta limitación. La PDS permanente, al demostrar que no puede ser gobernada por el principio de proporcionalidad, se vuelve difícil de explicar como una forma de castigo. ${ }^{81}$ La configuración institucional de la PDS permanente tiende a ser mejor explicada a través de propósitos degradantes y estigmatizantes.

Cuando la prohibición sólo afecta a los prisioneros durante el tiempo de su privación de libertad, la exigencia de la proporcionalidad se satisface mediante equiparación de la duración de la PDS y la duración de la primera. ${ }^{82}$ En la medida en que las condenas privativas de libertad son 'proporcionales' a la gravedad del delito (y algunas otras características de los condenados), considerar otros factores parecería arbitrario. No obstante, su aplicación a toda clase de delitos ha provocado críticas de todas formas. Tres cuestiones han sido particularmente problemáticas a la hora de justificar la PDS como castigo: 1) la ausencia de una conexión material entre el derecho que se suspende y el delito cometido (por ejemplo, sea fraude electoral o tráfico de estupefacientes); 2) la indiferencia ante la gravedad del delito (ya sea hurto u crimines contra la humanidad); y 3) la indiferencia ante la duración de la encarcelación del condenado (10 días o 10 años). ${ }^{83}$

\subsubsection{Conexión material}

La primera preocupación no dice relación con el principio de proporcionalidad sino con la conexión material entre el delito y el castigo. La imposición de la PDS a delitos con contenido electoral (e.g. fraude), o incluso a aquellos que tienen relación con el proceso democrático (e.g. abuso de poder), puede ser razonable, de acuerdo a algunos críticos. ${ }^{84}$ Sin embargo, su aplicación indiscriminada a todo tipo de delitos destruye la posibilidad de relacionar el castigo con el contenido del delito (to fit the crime), y sólo confirma que constituye un daño adicional injustificado a los condenados. ${ }^{85}$ Es llamativo el gran número de autores que son generalmente críticos de la PDS, pero que están de acuerdo en privar a aquellos condenados por delitos electorales de su derecho a sufragio. La explicación de ello, sin embargo, nunca se ha articulado en términos que no sean deficitarios. ${ }^{86}$ Por ejemplo, el voto minoritario en Hirst articula el siguiente argumento:

\footnotetext{
${ }^{81}$ Ver FLETCHER, "Disenfranchisement as punishment", cit. nota 4, p. 1896. Ver también BENNETT, "Giving Ex-Felons", cit. nota 43, par 30-2; KLEINIG; MURTAGH, "Disenfranchising Felons", cit. nota n 21, p. 221; LEVINE, "Does the Social Contract", cit. nota n' 21, p. 220.

${ }^{82}$ Ver REIMAN, "Liberal and republican", cit. nota ${ }^{\circ} 19$, p. 9. Ver también SCHALL, "The consistency of felon disenfranchisement", cit. nota $\mathrm{n}^{\circ} 21$, p. 75.

${ }^{83}$ Estos aspectos reproducen, en cierta medida, la crítica destacada por la naturaleza "general, automática e indiscriminada" de la legislación británica bajo el examen Hirst v The United Kingdom (No. 2), c. 70.

${ }^{84}$ Ver CHOLBI, "A felon's right to vote", cit. nota 17, p. 546. Ver también BENNETT, "Giving Ex-Felons", cit. nota 43, par 32; LÓPEZ-GUERRA, Democracy and Disenfranchisement, cit. nota 21, p. 116.

${ }^{85}$ Ver DEMLEITNER, "Continuing payment", cit. nota $\mathrm{n}^{\circ}$ 3, p. 791. Ver también BRENNER; CASTE, "Granting the Suffrage", cit. nota n² 21, p. 235; LEVINE, "Does the Social Contract", cit. nota ${ }^{\circ} 21$, pp. $217-$ 8 .

${ }^{86}$ Ver Hirst $v$ The United Kingdom (No. 2), c. 71. Ver también BECKMAN, L., The Frontiers of Democracy. The right to vote and its limits, London: Palgrave Macmillan, 2009, pp. 130-1.
} 


\section{Polit. Crim. Vol. 15, № 28 (Diciembre 2019), Art. 15, pp. 520-561. [http://politcrim.com/wp-content/uploads/2019/12/Vol14N28A15.pdf]}

"Es perfectamente concebible, por ejemplo, que una persona que ha sido condenada por fraude electoral [...] deba ser privada, por un tiempo, de su derecho a votar y a ser elegido en las elecciones. La razón para esto es que existe una conexión lógica y hasta natural entre el acto castigado y el propósito del castigo (que, aunque sea un castigo auxiliar, no deja de ser importante) que sirve de castigo a estos actos y como disuasión respecto de otros. Lo mismo no aplica [...] a ningún otro delito que conlleve una condena de privación de libertad., ${ }^{, 7}$

Una respuesta a este problema debe enfatizar el hecho de que el sentido de correspondencia material no está necesariamente relacionado con una teoría retributiva del castigo. La retribución no significa necesariamente lex talionis, ${ }^{88}$ sino que también puede adoptar la forma de 'proporcionalidad cardinal', o sea que la escala del castigo sea graduada con alguna relación a la gravedad de las conductas ilícitas. ${ }^{89}$ Esto es evidente cuando delitos como el robo o la violación son típicamente castigados con penas privativas de libertad. En contra de todas nuestras más básicas intuiciones, la privación de libertad, según esta idea, sólo procedería para castigar aquellos delitos contra la libertad, como el secuestro. La ausencia de una conexión material, por lo tanto, no puede ser un argumento contra el uso retributivo de la PDS. Este argumento no puede ser utilizado para justificar, sin razones adicionales, su uso como castigo de aquellos que han cometido delitos electorales o políticos.

\subsubsection{Gravedad}

La segunda crítica a la PDS como castigo es su aplicación indiscriminada, sin importar la gravedad del delito cometido. La exigencia de que la aplicación de la PDS sólo proceda respecto de condenados por delitos graves y no de aquellos condenados por delitos menores es central en la mayoría de los fallos de sobre PDS. ${ }^{90}$ Este argumento parece descansar en la idea de que el derecho a votar es fundamental en un sistema democrático y, por lo tanto, la PDS debe ser selectiva y sólo destinada a afectar a un grupo estrecho de condenados por delitos graves. ${ }^{91}$ La conclusión de este argumento es que una aplicación generalizada, que despoja del derecho a sufragio a todos los que estén privados de libertad, es desproporcionadamente inclusiva. Un homicida, un violador y un terrorista serán privados de su derecho a sufragio de igual forma que aquellos que han cometido delitos menores, como conducir bajo la influencia del alcohol, o como sucede con un hurto simple. ${ }^{92}$

\footnotetext{
${ }^{87}$ Voto de minoría en Hirst $v$ The United Kingdom (No. 2), c. 3 (destacado en el original).

${ }^{88}$ Ver e.g. WALDRON, J., "Lex talionis", Arizona Law Review, Vol. 34 (1992), pp. 25-51.

${ }^{89}$ VON HIRSCH; ASHWORTH, Principled Sentencing, cit. nota n ${ }^{\circ} 36$, pp. 182-3. Ver también CHOLBI, “A felon's right to vote", cit. nota ${ }^{\circ} 17$, p. 544.

${ }^{90}$ Es explícita y central tanto en Hirst v The United Kingdom (No. 2) como en Scoppola v Italy (No 3) como conclusión de un test de proporcionalidad. Roach $v$ Commonwealth lo acoge incluso como el propósito central de la PDS, conceptualizado en términos de castigar a condenados por delitos graves. Esto también está reconocido implícitamente por la Corte Suprema Sudafricana en NICRO (c. 67), y recibió mucha atención en el voto disidente de Sauvé v Canada (c. 119).

${ }^{91}$ CHOLBI desarrolla este argumento, pero extrañamente concluye que, dada la naturaleza fundamental del derecho a voto como expresión de auto-determinación, la retribución no puede validar la PDS ("A felon's right to vote", cit. nota $\mathrm{n}^{\circ} 17$, p. 548-50).

${ }_{92}$ Esta parece ser una de las grandes preocupaciones en el debate estadounidense, donde la PDS es aplicado significativamente a muchos delitos menores. Ver MANZA; UGGEN, Locked out, $\operatorname{cit}_{\text {. nota }}{ }^{\circ} 2$, p. 8 .
} 
Sin embargo, la razón de por qué la gravedad del delito debe ser considerada a la hora de aplicar la PDS no está claramente justificada. Podría ser posible realizar una distinción entre aquellos delitos que quebrantan el contrato social, 93 entendiendo éste como "un conjunto de reglas sin las cuales un orden político democrático no sería posible."94 Pero en ese escenario, uno forzosamente tiene que hacerse otra pregunta: ¿por qué las personas que no han cometido aquellos delitos se encuentran privados de libertad? La pregunta de cómo, bajo las circunstancias actuales, podemos encontrar diferencias entre un delito menor y uno más grave quedaría todavía sin responder.

La Corte Suprema de Canadá enfatizó este particular problema en su sentencia Sauvé v Canada. Primero, afirmó que cualquier límite que separe delitos menores de delitos graves es arbitrario. Y, segundo, observó que hay una ausencia de "correlación entre esta distinción (menor y grave) y el derecho a votar". ${ }^{95}$ Los delitos menores merecen un castigo y son violaciones a la ley tanto como los delitos graves, y ambos son castigados proporcionalmente. ¿Por qué la PDS sólo se debería aplicar a delitos graves? La Corte afirma que la distinción es guiada profundamente por la emoción y fracasa a la hora de responder la exigencia de racionalización del castigo. La conclusión de la Corte fue que "la única respuesta real que propone el gobierno a la pregunta '¿por qué dos años?' es que afectaría a un número menor de personas en lugar de una prohibición generalizada". ${ }^{96}$

Sin embargo, afirmar que no hay una distinción racional entre delitos menores y delitos graves no es necesariamente un argumento en defensa del derecho a sufragio de los privados de libertad, como fue concluido en Sauvé v Canada. También puede ser utilizado para apoyar una prohibición generalizada de sufragar desde la cárcel. El mejor ejemplo de esta línea argumentativa es la defensa de la PDS que el gobierno del Reino Unido realizó ante el TEDH en el caso Hirst $v$ The United Kingdom (No 2). Se sostuvo, primero, que debido a que "se debe establecer algún límite"97, el Parlamento es el mejor candidato para hacerlo. Segundo, se argumentó que la privación de libertad es el último recurso que tiene una sociedad para lidiar con la delincuencia, y que debe ser limitada sólo para aquellos

\footnotetext{
${ }^{93}$ Esa es la idea presentada por la opinión concurrente del Juez Caflisch en Hirst v The United Kingdom (No. 2), quien argumenta que la PDS debe ser restringida a los delitos más severos, porque simplemente no se puede asumir que cualquiera que ejecute una sentencia ha roto el contrato social (c. 7). Ver también Sauvé v Canada, c. 54.

${ }^{94}$ RAMSAY, "Voters should not be in prison", cit. nota ${ }^{\circ} 14$, p. 424.

${ }^{5}$ Sauvé v Canada, c. 55. Ver también LIPPKE, "The Disenfranchisement of Felons", cit. nota n 16, p. 563; PLAXTON; LARDY, "Prisoner Disenfranchisement", cit. nota n 9, p. 134; RAMSAY, "Faking democracy", cit. nota $\mathrm{n}^{\circ}$ 14, p. 6; HUGH M.; ROBERTS, J., "Written Evidence", en: Joint Committee on the draft Voting Eligibility (Prisoners) Bill Oral and Written Evidence, 2013.

${ }^{9}$ Sauvé v Canada, c. 55. La Corte notó la naturaleza política de la solución que buscaba el gobierno, y se negó abiertamente a involucrarse con ella. Ver EASTON, "Electing the electorate", cit. nota n 4, p. 452; SCHALL, "The consistency of felon disenfranchisement", cit. nota $\mathrm{n}^{\circ} 21$, p. 80; ORR, G.; WILLIAMS, G., "The People's choice: the prisoners franchise and the constitutional protection of voting rights in Australia", Election Law Journal, Vol. 8, № 2 (2009), p. 133.

${ }^{97}$ Hirst $v$ The United Kingdom (No. 2), c. 52.
} 


\section{Polít. Crim. Vol. 15, No 28 (Diciembre 2019), Art. 15, pp. 520-561. [http://politcrim.com/wp-content/uploads/2019/12/Vol14N28A15.pdf]}

sujetos que han cometido delitos más graves. ${ }^{98}$ Aquellos cuyas conductas no son castigadas con privación de libertad, el argumento concluye, ya han sido excluidos, por esa misma razón, de la categoría de los privados del derecho a sufragio. ${ }^{99}$ Aquellos que defienden una prohibición de sufragar dirigida sólo a los condenados por delitos graves que están cumpliendo penas privativas de libertad no han explicado cómo se puede establecer el límite entre ambos tipos de delito de manera racional ${ }^{100}$.

\subsubsection{Duración de la privación de libertad}

Finalmente, queda el argumento que parece ser el más importante. Este argumento sostiene que el problema con la imposición de la PDS, proviene de no tomar en cuenta la duración y el momento de la privación de libertad. Este factor es extraordinariamente relevante porque, a diferencia de como sucede, por ejemplo, con el caso del derecho a la libertad, el derecho a sufragio sólo puede ser ejercido durante las elecciones; y, por lo tanto, el castigo sólo podría experimentarse en aquellos días. Por esto, es completamente posible que una persona condenada a tres años de presidio, legalmente privado de su derecho a sufragio, no sufra la exclusión del proceso democrático, precisamente porque durante su privación de libertad no hubo elecciones. Por el otro lado, alguien que fue condenado a diez días de presidio podría estar despojado del derecho a participar en el proceso electoral, porque justamente en ese lapso de tiempo se celebraron elecciones. ${ }^{101}$ Este elemento produce resultados imprevisibles ${ }^{102}$, que dependen del momento en que una persona cumple su

\footnotetext{
${ }^{98}$ Ver BENNETT, "Penal disenfranchisement", cit. nota $\mathrm{n}^{\circ} 16$, p. 5. Ver también, más generalmente, HUSAK, D., "The Criminal Law as Last Resort", Oxford Journal of Legal Studies, Vol. 24, No 2 (2004), pp. 207-235; VAN ZYL SMIT; SNACKEN, Principles of European Prison Law, cit. nota $\mathrm{n}^{\circ}$ 61, pp. 86-97.

${ }^{99}$ Ver e.g. RAMSAY, "Voters should not be in prison", cit. nota ${ }^{\circ} 14$, p. 423. Sin embargo, como se notó en Hirst $v$ The United Kingdom (No. 2), c. 77 (y enfatizado en las opiniones concurrentes de los jueces Tulkens y Zagrebelsky) hay un factor de arbitrariedad en sustituir la gravedad de la privación de libertad por la aplicación de la PDS. El caso de las sentencias suspendidas, o libertad condicional, son paradigmáticos; no se atribuye a la PDS solo por abandono, sino también sobre otros elementos sociales. La arbitrariedad opera considerando las características personales del condenado (DAVISON, J., "Inside outcast: prisoners and the right to vote in Australia", Information and Research Services Parliamentary Library, Vol. 12 (2004), pp. 11). Ejemplos de esto incluyen la posibilidad de que algunos condenados puedan hacer reparaciones financieras en virtud del delito, o las estructuras de apoyo que un condenado tiene en torno a él o ella, y si estas permiten un castigo menos restrictivo que la privación de libertad. Ver GEDDIS, A., "Prisoner voting and rights deliberation: how New Zealand's Parliament failed", New Zealand Law Review (2011), p. 449. Ver también MUNN, N., "The limits of criminal disenfranchisement", Criminal Justice Ethics, Vol. 30, No 3 (2011), pp. 223-239, p. 225.

${ }^{100}$ La crítica del voto minoritario en Chester and McGeoch en contra del fallo del TEDH en Hirst es muy clara en este sentido: "[El TEDH] ha llegado a una posición muy curiosa [...]. Donde sea que se establezca el umbral para determinar la privación de libertad, pareciera que según su punto de vista hay ciertos delitos que son suficientemente graves que gatillar la privación de libertad, pero no lo suficientemente graves como para gatillar la privación del derecho a sufragio. Sin embargo, la base de este punto de vista jamás es articulada" (Voto minoritario en $R$. (on the application of Chester) $v$ Secretary of State for Justice and McGeoch v The Lord President of the Council (2013) UKSC 63, c. 135).

${ }^{101}$ Ver ORR, G., "Ballotless and behind bars: the denial of the franchise to prisoners", Federal Law Review, Vol. 26 (1998), p. 81. Ver también EASTON, "Electing the electorate", cit. nota n 4, p. 450; LACEY, N., "Denying prisoners the vote creates a barrier to their reintegration into society", Democratic Audit UK (2013).

${ }^{102}$ Chan Kin Sum v Secretary for Justice [2009] 2 HKLRD 166 and [2008] 6 HKC 486, c. 122.
} 
condena, lo que significa que la efectividad de la pena, en realidad, se vuelve independiente tanto de la duración de la privación de libertad como de la gravedad del delito. ${ }^{103}$

Para solucionar este problema de arbitrariedad, y asegurarse de que "las personas condenadas a penas de la misma duración sean sujetas a la misma exclusión del proceso electoral," ${ }^{104}$ la imposición de la PDS debería considerar los períodos electorales. Por ejemplo, la propuesta de despojar del derecho a sufragio sólo a aquellos criminales que están cumpliendo penas que tengan la misma extensión que el proceso electoral, e independiente del momento en que comienzan a cumplir la condena, apunta en esta dirección. La proporcionalidad de la PDS se determinaría en relación a los procesos electorales que el condenado ha perdido, y no en relación al tiempo que efectivamente pasó privado de libertad. ${ }^{105}$ Otra alternativa que apunta en la misma dirección demanda que la imposición de la PDS sea completamente autónoma de la privación de libertad. $\mathrm{Su}$ imposición directa como castigo independiente permitiría dirigirla precisamente en dirección a las elecciones que el condenado perderá por no tener su derecho a sufragio.

Se pueden formular algunas conclusiones a partir del análisis hasta ahora realizado. Reconociendo las limitaciones inherentes a cualquier castigo retributivo, la PDS puede ser defendida como una respuesta punitiva proporcional hacia aquellos que han cometido un delito. Las condiciones institucionales que debe asumir son tres. Primero, no puede ser impuesta de forma permanente o por períodos extraordinariamente largos después de que el condenado haya quedado en libertad. Segundo, aunque irrelevante si aplicamos la PDS sólo a delitos graves, la PDS debe ser aplicada con referencia a la proporcionalidad cardinal; o sea, debe afectar de mayor manera a aquellos que han cometido delitos más graves y viceversa. Finalmente, su imposición no puede depender de una relación arbitraria entre el día de la condena y el día de la elección y, por lo tanto, el criterio para determinar la proporcionalidad de la PDS debe responder al número de elecciones perdidas, en lugar de la duración de la pena. Adicionalmente, y repitiendo la discusión acerca de las diferencias existentes entre el castigo y las consecuencias colaterales de una condena penal, puede sostenerse que la PDS debe ser impuesta a través de una sentencia judicial. ${ }^{106}$

\subsection{El castigo expresivo como castigo democrático}

Asumiendo, sobre la base de las consideraciones anteriores, que la lógica retributiva no prohíbe la PDS como una forma de castigo, algunos autores han ofrecido una argumentación que defiende la PDS como una forma deseable de castigo. Han argumentado que la PDS actúa como una herramienta excepcional que permite expresar reproche contra delitos graves en una sociedad democrática. Como se verá, esta noción expresiva de la PDS, intenta evadir las críticas relacionadas con la degradación y la exclusión que experimentarían aquellos sujetos a sus efectos

\footnotetext{
${ }^{103}$ MUNN, "The limits of criminal disenfranchisement", cit. nota $\mathrm{n}^{\circ}$ 99, p. 225.

${ }^{104}$ MUNN, "The limits of criminal disenfranchisement", cit. nota $n^{\circ} 99$, p. 227.

${ }^{105}$ MUNN, “The limits of criminal disenfranchisement", cit. nota $n^{\circ} 99$, pp. 226-229.

106 Ver DEMLEITNER, "Continuing payment", cit. nota $\mathrm{n}^{\circ}$ 3, pp. 795-804. La opinión disidente en Scoppola v Italy (No. 3) apunta que la imposición judicial no es necesariamente requerida en virtud de la proporcionalidad, sino la naturaleza alegada de la PDS como el ejercicio de la reacción punitiva (c. 25).
} 


\section{Polít. Crim. Vol. 15, № 28 (Diciembre 2019), Art. 15, pp. 520-561. [http://politcrim.com/wp-content/uploads/2019/12/Vol14N28A15.pdf]}

\subsubsection{Privación del sufragio y reproche}

Una primera propuesta en este sentido puede ser encontrada en el trabajo de Jean Hampton, quien sostiene que la exclusión de ciertos condenados del voto permite expresar un compromiso con los valores democráticos sin necesariamente degradar. ${ }^{107}$ Hampton desarrolla una concepción del castigo que incluye a la retribución y otros aspectos expresivos, siguiendo la idea de Joel Feinberg, de que el castigo puede ser diferenciado de otras sanciones como "un mecanismo para la expresión de actitudes de resentimiento e indignación, y juicios de reprobación."108 Esa función expresiva de reproche público es esencial a la institución que conocemos como castigo. ${ }^{109}$

Hampton tiene conocimiento del problema democrático que presenta la PDS debido a la importancia democrática del derecho a sufragio. Probablemente, esa es la razón por la cual ella comienza su defensa de la PDS afirmando el vínculo interno que existe entre retribución e igualdad. Un condenado ataca la idea de igualdad al dañar los "intereses de otro individuo para alcanzar sus propios propósitos [...] a la vez que le dice a ese individuo 'yo estoy aquí arriba y tú estás allá abajo; así que puedo utilizarte para mis propios propósitos'."110 Los delitos son acciones injustas porque son, en sí mismos, acciones que expresan un desprecio hacia las víctimas. El castigo, desde su punto de vista, es exigido como una forma de defender el igual valor e importancia de las víctimas y negar la pretensión del condenado de posicionarse por sobre ellas. La proporcionalidad de la pena, en este contexto, expresa el igual valor de la víctima que ha sido afectada por el delito. Pero este propósito no puede ser perseguido o alcanzado degradando al condenado con un "trato que lo representa como una persona inferior o menos humana." ${ }^{111}$ Es importante, para estos efectos, establecer que el repudio inherente al castigo no está dirigido al condenado en sí mismo, sino que sólo a su conducta. Eso es lo que diferencia al castigo de la venganza, sostiene Hampton. ${ }^{112}$ Si se dirige la PDS a la persona de los condenados en lugar de a su conducta, no encontraríamos tratándolos "como forajidos - personas viven fuera del Estado y fuera de la comunidad." "En contraste, para Hampton la PDS puede ser respetuosa

107 Ver HAMPTON, "Punishment, Feminism", cit. nota $\mathrm{n}^{\circ} 16$. Ver una crítica a su propuesta en ROTHCHILD, J., "Dispenser of the mercy of the government: pardons, justice, and felony disenfranchisement", Journal of Religious Ethics, Vol. 39, № 1 (2011), pp. 62-4.

${ }^{108}$ FEINBERG, "The expressive function of punishment", cit. nota ${ }^{\circ} 27$, p. 98 (énfasis añadido).

${ }^{109}$ Ver HAMPTON, J., "An expressive theory of retribution", en: CRAGG, W. (ed), Retributivism and its Critics, Stuttgart: Franz Steiner Verlag, 1992, pp. 17-23. Esta función podría ayudar o perjudicar otros propósitos (por ejemplo, rehabilitación), pero no es necesariamente el caso. Hampton generalmente está comprometido con la idea de que el castigo penal tiene dos funciones particulares: la función expresiva de reproche y la función preventiva de educación moral.

${ }^{110}$ HAMPTON, "Punishment, Feminism”, cit. nota ${ }^{\circ} 16$, pp. 38-9.

${ }^{111}$ HAMPTON, "Punishment, Feminism", cit. nota $n^{\circ} 16$, p. 39.

${ }^{112}$ Ver generalmente HAMPTON, "An expressive theory", cit. nota $\mathrm{n}^{\circ} 109$. Comparar con WHITMAN, J. Q., Harsh Justice. Criminal punishment and the widening divide between America and Europe, New York: OUP, 2003 , p. 21

${ }^{113}$ HAMPTON, "Punishment, Feminism", cit. nota $n^{\circ} 16$, p. 39. Ella continua, de una forma que podría ser vista como una respuesta a la idea del mal carácter de los condenados, de la siguiente forma: "Yo considero que esta forma de entender el disenfranchisement de los prisioneros es abusiva, degradante, e injusta: abusiva porque tiene un mensaje de odio, degradante por lo que se refiere a su 'mala' naturaleza (de manera que este mensaje se asemeja al destierro) e injusta, porque es indiferente a las posibles fuerzas sistémicas que podrían 
respecto del estatus de los condenados como sujetos con igual valor. ${ }^{114}$ Para lograr eso exitosamente, el castigo debe cumplir la función de kolasis, que consiste en poner al condenado en su lugar y no puede consistir en una forma de degradación. ${ }^{115}$

Su argumento se desarrolla sosteniendo la relevancia de la conexión material entre el delito y el castigo, por un lado, a través del reconocimiento de la importancia democrática del derecho a sufragar; y, por el otro lado, insistiendo en la necesidad de identificar ciertos delitos que son "destructivos de los valores y el funcionamiento de una sociedad democrática." $" 116$ Delitos contra el Estado y las instituciones democráticas, delitos de odio racial y delitos contra las mujeres, son buenos candidatos para esta categoría especial de delitos merecedores de la PDS. Ella es una respuesta adecuada a estos tipos de delito, en formas que no son cubiertas por la privación de libertad. Esto es así, porque la PDS expresa repudio respecto de la dimensión política del acto. Simbólicamente, despojar a este grupo de condenados de su derecho a sufragio, y sólo a ellos, expresa el mensaje de que quien no acepte los valores de igualdad democrática no puede participar en la toma de decisiones de la comunidad. ${ }^{117}$ Esta conexión expresiva entre el delito y la forma del castigo constituyen una razón para exigir una conexión material que, como se viera anteriormente, no ha había recibido una satisfactoria justificación ${ }^{118}$.

\subsubsection{Privación del sufragio y responsabilidad}

provocar dicha conducta criminal" (36). Ver también SIGLER, "Defensible disenfranchisement", cit. nota ${ }^{\circ}$ 15, pp. 16-7.

${ }^{114}$ Cf. LIPPKE, "The Disenfranchisement of Felons", cit. nota ${ }^{\circ} 16$, p. 564.

${ }^{115}$ Ver WHITMAN, Harsh Justice, cit. nota ${ }^{\circ} 112$, pp. 21-2.

116 HAMPTON, "Punishment, Feminism", cit. nota $\mathrm{n}^{\circ} 16$, p. 41. Ver también LIPPKE, "The Disenfranchisement of Felons", cit. nota 16, p. 562; LAVI, S., "Citizenship revocation as punishment: on the modern duties of citizens and their criminal breach", University of Toronto Law Journal, Vol. 61 (2011), pp. 783-810, p. 800.

${ }^{117}$ En palabras de Hampton: “¿Qué mensaje político se envía si lo dejamos votar? Yo diría que uno muy malo: a pesar del hecho de que intentó destruir nuestro gobierno y mostró desprecio por los valores que lo respaldan, lo dejaremos participar en él de todas formas. Esta no es forma de defender nuestros valores, o de apoyar una forma democrática de gobierno" (HAMPTON, "Punishment, Feminism", cit. nota n 16, p. 41). Ver también LÓPEZ-GUERRA, Democracy and Disenfranchisement, cit. nota nº 21, p. 114.

${ }^{118}$ El TEDH, en Hirst $v$ The United Kingdom (No2), reprodujo esta teoría, sosteniendo que una sociedad democrática "se puede proteger a sí misma frente a actividades dirigidas a destruir los derechos y libertades," usando para este propósito las "restricciones a los derechos electorales [...] impuestos a un individuo quien ha, por ejemplo, abusado seriamente de un cargo público o cuya conducta amenaza con destruir el imperio del derecho o sus fundamentos democráticos" (c. 71). El voto disidente en Sauvé v Canada adopta también este punto de vista, y cita explícitamente a Hampton cuando expresa que: "La privación de libertad simboliza un rechazo a la conducta antisocial del condenado e articula la esperanza que tiene la sociedad en la rehabilitación de este individuo por medio de su separación del resto de la comunidad. La privación de libertad por sí sola, sin embargo, deja que aquellos condenados por delitos graves mantengan su derecho a participar en el proceso electoral abierto a todos los ciudadanos que obedientes de la ley. Esto revela una paridad política entre aquellos condenados por los peores delitos de la sociedad y sus víctimas. Una exclusión de las elecciones, por el otro lado, indica un rechazo a la conducta antisocial del condenado y envía el mensaje de que aquellas personas condenadas por causarle a otros las peores formas de indignidad serán despojados de, al menos, un aspecto de esta igualdad política de los ciudadanos - el derecho a sufragio. Puede decirse que, en este contexto, amabilidad hacia el condenado puede constituir un acto de crueldad hacia sus víctimas, y la comunidad en sí” (c. 181). Ver también Sauvé v Canada, c. 119. 


\section{Polit. Crim. Vol. 15, № 28 (Diciembre 2019), Art. 15, pp. 520-561. [http://politcrim.com/wp-content/uploads/2019/12/Vol14N28A15.pdf]}

El argumento de Hampton reafirma la procedencia de la PDS en relación a delitos contra los valores democráticos, pero no avala su procedencia respecto de todo tipo de delitos. Sin embargo, como han destacado otros autores, la comisión de cualquier delito expresa un desprecio hacia los resultados del proceso democrático y, como tal, cualquier delito, independiente de su identidad material anti-democrática, sería un atentado contra los valores mencionados. ${ }^{119}$ Esto sería cierto especialmente en el caso de "aquellos condenados cuyos antecedentes muestran que generalmente no están dispuestos a seguir las leyes promulgadas por los gobiernos democráticos." ${ }^{120}$ En este sentido, la propuesta de Christopher Bennett comparte alguna de las premisas de Hampton, aunque se diferencia de ella en la medida que extiende el campo de aplicación de la PDS.

Bennett sostiene que castigar al condenado es una forma de hacer que la persona asuma responsabilidad por sus actos. ${ }^{121}$ La responsabilidad, sin embargo, sólo puede tener sentido en el contexto de una comunidad $\mathrm{y}$, simultáneamente, para que los condenados sean tratados como miembros de una comunidad, deben ser efectivamente responsables de sus actos. Bennett sugiere que la responsabilidad es una parte de lo que significa pertenecer a una comunidad en la misma medida en que participar en la toma de decisiones es también una parte importante de la responsabilidad de pertenecer a una comunidad, concluyendo que sólo alguien que está 'dentro' de la comunidad puede ser responsable, tanto siendo castigado, como participando en la toma de decisiones. ${ }^{122}$ Según Bennett, el castigo, hablando en forma general, produce el efecto de incluir al condenado dentro de la comunidad, en lugar de excluirlo de la misma. Esta afirmación, sin embargo, aplicaría a cualquier forma de castigo y no sólo a la PDS.

Bennett continúa - en lo que probablemente constituye la parte más polémica de su posición - sosteniendo que la suspensión del derecho a sufragio constituye un excelente candidato para hacer responsable a alguien, dado que la utilización del símbolo que utilizamos para expresar reproche, en este caso el derecho a sufragio, debe permitir al condenado experimentar simbólicamente, un distanciamiento de la comunidad. ${ }^{123}$ Luego, concluye que "el derecho a votar puede ser removido temporalmente para expresar la gravedad de una conducta, sin que sea [por esa razón] removida la ciudadanía en sí misma." ${ }^{24} \mathrm{Si}$ el delito constituye una ruptura en la relación entre el condenado y la comunidad, la forma de reafirmar dicha relación, es despojando al condenado de su derecho a sufragio, lo que se deriva de la conexión específica de este último con la idea de pertenencia a la comunidad.

\footnotetext{
${ }^{119}$ Ver e.g. LIPPKE, “The Disenfranchisement of Felons”, cit. nota n ${ }^{\circ} 16$, pp. 546-7.

${ }^{120}$ LIPPKE, "The Disenfranchisement of Felons", cit. nota n ${ }^{\circ}$ 16, p. 566.

${ }^{121}$ Ver e.g. DUFF, R. A., "Inclusion, exclusion and the criminal law", Policy Futures in Education, Vol. 1, No 4 (2003), pp. 699-715.

${ }^{122}$ BENNETT, "Penal disenfranchisement", cit. nota $\mathrm{n}^{\circ} 16, \mathrm{p}$. 6 . Su teoría del castigo penal está desarrollada en BENNETT, C., The Apology Ritual, Cambridge: CUP, 2008.

${ }^{123}$ BENNETT, "Penal disenfranchisement", cit. nota $\mathrm{n}^{\circ} 16$, p. 7. Similarmente, SIGLER sostiene que la PDS "es ideal para reafirmar los valores de la ciudadanía democrática liberal. Precisamente porque el derecho a voto es un símbolo poderoso de la responsabilidad del ciudadano, su negación expresa forzadamente la significancia política de la ruptura de la confianza civil" ("Defensible disenfranchisement", cit. nota $\mathrm{n}^{\circ} 15$, pp. 18).
}

${ }^{124}$ BENNETT, "Penal disenfranchisement", cit. nota ${ }^{\circ} 16$, p. 7. 
Bennett, sin embargo, sostiene que la gravedad del delito sí debe ser un criterio para limitar la aplicación de la PDS bajo consideraciones de proporcionalidad. Como el derecho a sufragio es un derecho importante en una comunidad democrática, la PDS "debería reservarse para aquellos delitos más graves que amenazan con socavar el estatus de una persona como miembro de la comunidad política". ${ }^{125}$ Bennett parece estar sosteniendo que la ciudadanía sólo puede ser mantenida a través del hecho de que el condenado es comunicativamente incluido a través del castigo que expresa su responsabilidad. Este rol queda reforzado con la aplicación de la PDS, dado que ésta está reservada sólo para delitos de mayor gravedad.

\subsubsection{La privación del sufragio como un castigo expresivo}

La justificación de la PDS como una forma adecuada de castigo reside en su potencial para expresar repudio respecto de la dimensión política del delito. En el caso de Hampton, este castigo se destaca por su carácter no degradante y por su aplicación a condenas por delitos con connotación democrática. En el caso de Bennett, la PDS está conectada con la pertenencia de los condenados al resto de la comunidad. Sin embargo, la ventaja expresiva de la PDS, en relación con otras formas de castigo (como la privación de libertad), no está totalmente completamente clara, lo que hace razonable agregar algunas ideas.

El problema con justificar una forma de castigo es, en cierta medida, similar al problema general de justificación del maltrato (hard treatment) asociado al castigo en la teoría del castigo. Dentro del marco de la teoría retributiva del castigo, la elección de la forma del castigo no está determinada por su potencial para prevenir el delito. En este contexto, podría cuestionarse la exigencia de infligir sufrimiento como la forma en que ese reproche por el delito se debe manifestar. Dicho de otra forma: si el castigo es reproche hacia un delito, es innecesario que el castigo inflija sufrimiento. De todos modos, este será el caso si se considera que el maltrato es un mal necesario, derivado del hecho de que no hemos desarrollado un "mecanismo simbólico menos doloroso" para expresar reproche. ${ }^{126}$

Las respuestas a este problema, sobre por qué debemos maltratar a nuestros conciudadanos, han provocado un nutrido debate. Los propósitos de protección social del castigo, en particular su efecto disuasivo, han sido postulados como respuesta a la pregunta de por qué el reproche expresado en la sentencia debe ser seguido por un maltrato. ${ }^{127}$ De acuerdo a este razonamiento, si ya está claro que la PDS no opera disuasivamente respecto de futuros delitos, no se podría justificar la privación del derecho a votar. Sin embargo, en una justificación alternativa del maltrato, la expresión del reproche depende de la imposición de

\footnotetext{
${ }^{125}$ BENNETT, "Penal disenfranchisement", cit. nota $n^{\circ} 16$, p. 8.

${ }^{126}$ Ver FEINBERG, "The expressive function of punishment", cit. nota $n^{\circ} 27$, pp. 114-6. Esta cuestión es evidentemente ajena a las concepciones de castigo penal degradante, en el cual los 'tratos severos' son autorizados e incluso exigidos por la pérdida del estatus moral del condenado. Ver e.g. MORRIS, C., "Punishment and the loss of moral standing", Canadian Journal of Philosophy, Vol. 21, № 1 (1991), pp. 5380, passim.

${ }^{127}$ Ver VON HIRSCH, A., "Punishment, Penance, and the State", en: MATRAVERS, M. (ed), Punishment and Political Theory, Oxford: Hart, 1999, pp. 69-70.
} 


\section{Polít. Crim. Vol. 15, № 28 (Diciembre 2019), Art. 15, pp. 520-561. [http://politcrim.com/wp-content/uploads/2019/12/Vol14N28A15.pdf]}

un sufrimiento para que verdaderamente constituya cumpla su propósito. La imposición de un maltrato, desde esta perspectiva, lleva a cabo la expresión de reproche. ${ }^{128}$

Hampton y Bennett parecen sugerir que el potencial expresivo de la PDS es óptimo respecto de otras formas de castigo, que pueden ser consideradas, al menos en este aspecto, como deficientes. Para ello es esencial entender correctamente la cuestión de la proporcionalidad. Esta no requiere que se provoque la misma cantidad de sufrimiento que aquella producida a las víctimas por el delito. Pero sí requiere una correspondencia con el aspecto de reproche del castigo. Esto implica que los delitos más graves deben recibir una desaprobación más fuerte, pero no necesariamente deben ser seguido de castigos más duros. ${ }^{129}$ La PDS, de acuerdo a estas premisas, puede ser presentada como una forma ideal de castigo expresivo. Tiene un déficit respecto al aspecto del maltrato, como se manifiesta en el poco sufrimiento que produce en los condenados, pero esto es irrelevante desde el punto de vista de una teoría retributiva del castigo enfocada en el carácter expresivo de ésta. Esta funcionalidad reducida de los otros aspectos, puede ser compensada por su extraordinario desempeño en el aspecto central del castigo: ofrece una excelente rendimiento en su expresividad. ${ }^{130}$

Vista de esta manera, la PDS no es completamente independiente de la privación de libertad. El rol de la PDS, desde el punto de vista de la teoría expresiva de la pena, puede ser reafirmar las señales morales comunicadas a través de la privación de libertad. ${ }^{131} \mathrm{El}$ voto disidente en Sauvé v Canada enuncia el argumento con envidiable claridad:

"La comisión de delitos graves da lugar a una suspensión temporal de este vínculo (entre el condenado y la comunidad): a nivel físico, esto se manifiesta en la privación de libertad y la privación de otras libertades normalmente ejercidas por los ciudadanos y, a nivel simbólico, esto se manifiesta en la privación del derecho a sufragio por un cierto lapso. La dimensión simbólica es, por lo tanto, una manifestación de la desaprobación por parte de la comunidad de una conducta delictual grave."132

\footnotetext{
${ }^{128}$ Ver MAÑALICH, J. P., "El derecho penitenciario entre ciudadanía y los derechos humanos", Derecho y Humanidades, Vol. 18 (2011), pp. 163-178, p. 171.

${ }^{129}$ FEINBERG, "The expressive function of punishment", cit. nota $\mathrm{n}^{\circ} 27, \mathrm{p} .118$.

${ }^{130}$ Ver BENNETT, C.; VIEHOFF, D., "Prisoner voting for the final general election before release is a solution that balances concerns about democratic rights", Democratic Audit UK (2013). La propuesta del gobierno en Chan Kin Sum v Secretary for Justice articula esta idea como sigue: "El castigo penal consiste en al menos dos elementos constitutivos: (1) el elemento de reproche o culpa y (2) el elemento de privación o maltrato (hard treatment). La PDS sirve primariamente al propósito del reproche, mientras que la privación de libertad sirve el propósito del maltrato. PDS es una forma de reproche que contiene la reprobación de la sociedad respecto de la conducta delictual del sujeto" (c. 84).

${ }_{132}^{131}$ MANFREDI, "In Defence of", cit. nota n ${ }^{\circ} 15$, p. 274.

${ }^{132}$ Voto disidente en Sauvé v Canada, c. 119. Ver también NICRO, donde la Corte afirmó "que al nivel de políticas públicas es importante para el gobierno poder denunciar las conductas criminales y comunicar al público que los derechos que tienen los ciudadanos están relacionados a sus deberes y obligaciones como ciudadanos." (c. 57). Las conclusiones del informe del Joint Committee on the Draft Voting Eligibility (Prisoners) Bill, destinado a discutir el problema de la PDS para conducir a un escrutinio pre-legislativo en la legislación británica, asumen una posición similar. Siguiendo la idea de que el derecho a sufragio implica un ejercicio de poder por parte del condenado sobre el resto de los ciudadanos (ver WALDRON, J., "Oral Evidence", en: Joint Committee on the draft Voting Eligibility (Prisoners) Bill Oral and Written Evidence, 2013), el Comité afirmó que la PDS es un acto simbólico basado en una "conexión intuitiva entre ejercer el
} 
En resumen, la PDS depende del potencial que este tipo de castigo tiene para expresar el reproche que simbólicamente no puede ser expresado por la simple privación de libertad. En un marco retributivo, la PDS operaría de las siguientes formas: 1) reafirmando el valor del resultado de un proceso democrático que los condenados han infringido; 2) expresando la importancia del ejercicio de los derechos democráticos que han sido suspendidos; 3 ) expresando repudio hacia aquellos que han denigrado el proceso democrático o alguno de sus principios fundamentales.

\section{Sobre los límites del castigo democrático}

Hampton y Bennett presentan a la PDS como una forma democrática de castigo. Es concebida como un mecanismo que protege los valores democráticos y respeta el hecho de que los condenados, pese a ser privados de su derecho a sufragio, siguen siendo miembros iguales dentro de los márgenes de una comunidad política. Esta última sección del trabajo examina críticamente dicha postura, sugiriendo, por el contrario, que la concepción expresiva de la PDS tiene profundos problemas, expresa las señales equivocadas, y es incompatible con una concepción democrática del castigo.

\subsection{Inclusión por exclusión e inclusión por inclusión}

El núcleo del argumento expresivo está en que la PDS repudia el delito, pero a la vez trata al condenado con respeto, sin degradarlo o excluirlo. La importancia de esto sería que expresa nuestro compromiso con los valores democráticos que han sido quebrantados con el delito. Sin embargo, es poco claro y difícil de explicar cómo la exclusión política de los condenados (a través de la PDS) es capaz de simbolizar su inclusión en la comunidad, o el respeto que se les debe como ciudadanos. ${ }^{133}$ También es difícil explicar cómo esta forma de castigo honra los valores democráticos, como sostienen sus defensores. ${ }^{134}$ La razón tras esta incomprensión podría residir en que la existencia de una obscura conexión, y un lazo paradójico entre la exclusión y la inclusión. De esta manera mediante la exclusión del sufragio se produciría la inclusión en la ciudadanía. Sin embargo, hasta ahora, pese a los esfuerzos de Hampton y Bennett, este lazo no ha sido explicado de forma convincente. En este sentido, por ejemplo, Heather Green crítica a la PDS "precisamente porque se le impone al condenado un estatus político desigual [y] la sociedad compra el simbolismo [asociado a la PDS] a expensas del compromiso con el principio de igualdad política." ${ }^{\prime 35} \mathrm{El}$ simbolismo encarnado en la PDS no es un simbolismo igualitario sino que triunfa precisamente frente al principio de igualdad.

derecho a sufragio y tener un poder [aunque sea minúsculo] sobre cómo la sociedad se gobierna" (JOINT COMMITTEE ON DRAFT VOTING ELIGIBILITY (PRISONERS) BILL, Report (2013, HL 103, HC 924), p. 42). Esto puede ser explicado en los siguientes términos: "si un miembro ha violado gravemente las reglas básicas, parece auto evidentemente apropiado quitarle a ese miembro el control parcial que tiene sobre las decisiones de aquella asociación." (p. 43).

${ }^{133}$ Ver EASTON, "Electing the electorate", cit. nota ${ }^{\circ} 4$, p. 450.

${ }^{134}$ Ver BECKMAN, L., The Frontiers of Democracy, cit. nota n ${ }^{\circ} 86$, p. 138.

${ }^{135}$ LARDY, "Prisoner disenfranchisement", cit. nota n ${ }^{48,}$ p. 528. 


\section{Polít. Crim. Vol. 15, № 28 (Diciembre 2019), Art. 15, pp. 520-561. [http://politcrim.com/wp-content/uploads/2019/12/Vol14N28A15.pdf]}

Pero el problema de la PDS expresiva no es sólo su fracaso a la hora de cumplir su propósito como un castigo no degradante, sino también que quebranta al mismo tiempo su propia promesa. En este sentido, la PDS, como mensaje democrático, es contradictorio ${ }^{136}$. Si una teoría expresiva de castigo se proclama democrática, sería mucho más natural defender el derecho a sufragio de los condenados, esto es su inclusión política, en lugar de su exclusión política, como es una reafirmación de los valores democráticos. El mensaje democrático e inclusivo sería mucho más comprensible tanto para el propio condenado como por la comunidad en general. También sería una mejor forma de reafirmar los valores democráticos como una manera simbólica de oponerse a las fuerzas, impulsos y conductas antidemocráticas: "La PDS es un símbolo de rechazo, no de reconciliación; un símbolo de indiferencia, en lugar de comunidad; un símbolo de dominación en lugar de igualdad." La teoría expresiva simplemente no va en la dirección correcta.

De acuerdo a un entendimiento más democráticamente intuitivo del retribucionismo expresivo, la señal de inclusión de los condenados dentro de la comunidad política se lleva a cabo manteniendo sus derechos políticos durante el lapso que dure su privación de libertad. Así, se alcanza la inclusión simbólica no a través de la exclusión, sino que a través de la inclusión política. Por ejemplo, Anthony Duff ha defendido vehementemente esta postura:

"El derecho a sufragio [...] es central respecto de nuestra identidad como ciudadanos [...]: remover ese derecho [...] es, simbólicamente, muy serio, ya que marca la exclusión temporal o permanente de la calidad de ciudadano con plenos derechos, y por lo tanto de miembro de la comunidad política. La ley [...] tiene como propósito protegernos y unirnos como ciudadanos; en una democracia, la ley se presenta como 'nuestra' ley - como ley común de una comunidad que se comunica con sus miembros a través de la voz de ciudadanos que hablan consigo y entre sí, no en la voz de un soberano externo que exige su obediencia [...]. Pero cuando un ciudadano pierde su derecho a sufragio, pierde su parte en aquella voz: ahora la ley no puede presentarse como la ley de un 'nosotros' si aquel ciudadano no pertenece a ese 'nosotros'; en este caso la ley se presenta a través de la voz de 'ellos,' esto es, del grupo que lo ha excluido." 138

Sin embargo, debe enfatizarse que esto no es un problema solamente de simbolismo político. Despojar del derecho a sufragio es también una política criminal inadecuada, porque no cumple su rol expresivo, ni disuade, incapacita o rehabilita y sólo puede producir

\footnotetext{
${ }^{136}$ La Corte Suprema Canadiense argumentó en este sentido cuando sostuvo que se "[...] entiende esta conexión (entre [por un lado,] la 'legitimidad de la ley y la obligación de obedecer la ley' y [, por otro lado,] 'el derecho de todos los ciudadanos a votar') al revés cuando tratan de argumentar que despojar a una persona de su derecho a una voz en el gobierno le enseñará a obedecer la ley. El 'mensaje educativo' que se pretende enviar por el gobierno al privar a los reos de su derecho a sufragio es anti-democrático y, además, internamente auto-contradictorio. Negarle a un ciudadano su derecho a sufragio es negar la misma base de legitimidad democrática [...]" (Sauvé v Canada, cc. 31-2, énfasis añadido).

${ }^{137}$ NOTE. "The Disenfranchisement of ex-felons", cit. nota n ${ }^{\circ} 21$, p. 1317.

${ }^{138}$ DUFF, R. A., "Introduction: crime and citizenship", Journal of Applied Philosophy, Vol. 22, № 3 (2005), pp. 213. Ver también MAÑALICH, J. P., "Pena y ciudadanía", en: KINDHAUSER, U.; MAÑALICH, J.P., Pena y Culpabilidad en el Estado democrático de Derecho, Buenos Aires: Editorial BdF, 2011, pp. 116-142, passim; ZIEGLER, "Legal outlier”, cit. nota n 9, p. 208; Sauvé v Canada, cc. 38-40.
} 
el efecto de degradar, excluir y estigmatizar a los condenados, dañando al mismo tiempo la legitimidad de la imposición de un castigo que dice ser democrático. Como pronunció la Corte Canadiense, "un gobierno que condiciona el derecho a sufragio a una porción determinada de sus ciudadanos, es un gobierno que [...] corroe la base misma de su derecho a condenar y castigar a los que infringen la ley".

Habiendo formulado una crítica a la justificación de la PDS como un castigo expresivo, lo que queda de este trabajo se enfocará en explicar el problema que la PDS presenta para una concepción democrática del castigo.

\section{2. ¿Puede el castigo ser democrático?}

Los intentos para desarrollar una teoría democrática del castigo no son fáciles de encontrar. Usualmente la teoría del derecho penal se concentra en cuestiones tales como bajo qué circunstancias debe imponerse el castigo, y se despreocupa de la cuestión de quién tiene el poder de hacerlo o bajo qué condiciones el castigo puede ser legítimo. ${ }^{140}$ Hay en la literatura anglosajona dos posturas sobre el castigo que enfatizan algunas de estas dimensiones y la vinculan al derecho a sufragio de los sujetos privados de libertad. La primera considera que la democracia y los derechos democráticos deben ser protegidos no sólo contra el crimen, sino también contra el uso desproporcionado del poder punitivo del Estado. La segunda establece, de forma similar que Bennett, que para que el castigo sea democrático, debe provenir de una comunidad de la que el condenado es miembro.

Una primera propuesta proviene de Corey Brettschneider, quien para responder la pregunta acerca de la legitimidad del castigo, propone utilizar el esquema del contractualismo de Rawls. ${ }^{141}$ Según su concepción del 'contractualismo democrático', los derechos democráticos no sólo incluyen derechos para participar en el proceso de producción del derecho, sino también derechos que limitan la coacción estatal. ${ }^{142}$ En este contexto, estipula que para que el castigo sea legítimo, este debe ser aceptable para sujetos razonables que actúan bajo el principio de reciprocidad. No postula que el condenado deba aceptar el castigo que se le impone, sino que el castigo podría ser aceptado si el sujeto en cuestión se encontrara motivado a equilibrar sus intereses con los intereses de los demás miembros de la sociedad. ${ }^{143}$

Esta idea descartaría las concepciones que aseguran que los condenados no tienen derechos. Por el contrario, bajo un marco contractualista, los condenados tienen derecho a ser castigados razonablemente, un derecho que sólo es compatible con su pertenencia a la comunidad de ciudadanos. Esto implica, por ejemplo, la prohibición del uso de violencia innecesaria contra los prisioneros y de medidas que no se corresponden con los intereses de

\footnotetext{
${ }^{139}$ Sauvé v Canada, c. 34.

${ }^{140}$ Ver DE GREIFF, P., "Deliberative democracy and punishment", Buffalo Criminal Law Review Vol. 5, № 2 (2002), pp. 373-5. Ver también BRETTSCHNEIDER, C., "The rights of the guilty", Political Theory, vol. 35 (2007), p. 175.

${ }^{141}$ Ver BRETTSCHNEIDER, "The rights of the guilty", cit. nota $\mathrm{n}^{\circ} 140$. Ver también BRETTSCHNEIDER, C., Democratic Rights. The substance of self-government, Princeton: Princeton University Press, 2007.

${ }^{142}$ Ver BRETTSCHNEIDER, C., Democratic Rights, cit. nota ${ }^{\circ}$ 141, Cap. 2.

${ }^{143}$ BRETTSCHNEIDER, "The rights of the guilty", cit. nota $n^{\circ} 140$, p. 179.
} 


\section{Polít. Crim. Vol. 15, No 28 (Diciembre 2019), Art. 15, pp. 520-561. [http://politcrim.com/wp-content/uploads/2019/12/Vol14N28A15.pdf]}

la sociedad. Simultáneamente, esta idea exige respeto por todos aquellos derechos que se pueden ver afectados por la privación de libertad, desde la libertad de expresión hasta el derecho a sufragio. ${ }^{144}$ Esto se sigue del hecho de que sujetos razonables también repudiarían la limitación innecesaria de esos derechos democráticos. ${ }^{145}$

Una segunda propuesta es la de Anthony Duff, quien también se ha comprometido a justificar un derecho penal de carácter democrático. Su preocupación principal ha sido explicar cómo el castigo pueda funcionar como una respuesta inclusiva a la comisión de delitos. ${ }^{146}$ Duff reconoce que por definición el derecho penal es una práctica excluyente. ${ }^{147}$ No es difícil, por ejemplo, notar los aspectos dramáticamente excluyentes del encarcelamiento. La privación de libertad constituye una exclusión física respecto de la vida normal en comunidad, comunicándole a los prisioneros que "no pertenecen a la comunidad ordinaria de ciudadanos." "148 Esa comunicación es aún más fuerte cuando los condenados pierden - además de su libertad - los derechos de participación política y el derecho a sufragio en particular. ¿Cómo puede una respuesta punitiva ser inclusiva? ¿Cómo podemos desarrollar una forma de luchar contra las tendencias excluyentes del derecho penal y construir un modelo de castigo que tenga una respuesta inclusiva al crimen? ${ }^{149}$

La propuesta de Duff concibe al castigo como un mecanismo para hacer responsables a los condenados, basado en su pertenencia a una comunidad normativa. Los condenados son llamados para que asuman responsabilidad por quebrantar el derecho, "a través de un derecho que dice ser su derecho." 150 Esto se alcanza restringiendo el castigo en concordancia con un conjunto de factores de inclusión que constituyen la pertenencia de una persona dentro de la comunidad (factores políticos, materiales, normativos y linguiísticos). Cuando el castigo afecta al condenado, excluyéndolo de estas dimensiones de la vida en comunidad, o tratándolo en formas que son incompatibles con su membresía, los postulados de la escuela abolicionista comienzan a volverse persuasivos, sostiene Duff. ${ }^{151}$ La inclusión es especialmente crucial para la dimensión comunicativa del castigo. Sin inclusión, el castigo no puede involucrar reproche, pues se transforma en un mecanismo de mero control. ${ }^{152}$

Duff concibe a la PDS como algo que corresponde a la lógica del 'derecho penal del enemigo', o sea una doctrina que está lejos de respetar a los ciudadanos y de considerarlos

\footnotetext{
${ }^{144}$ Ver BRETTSCHNEIDER, "The rights of the guilty", cit. nota $n^{\circ} 140$, pp. 187-90.

${ }^{145}$ A pesar de sus virtudes, consistentes en el respeto por la autonomía de aquellos sujetos al poder punitivo del Estado y la protección de sus derechos democráticos, el aspecto específicamente democrático de la legitimidad del castigo penal en este punto de vista está desarrollado sólo en su faz negativa, debido probablemente a la metodología contractualista utilizada. El énfasis principal se pone en la protección de los derechos democráticos del condenado, despreocupándose de las exigencias democráticas positivas, más amplias del derecho penal.

${ }^{146}$ Ver DUFF, "Inclusion, exclusion and the criminal law", cit. nota $\mathrm{n}^{\circ} 121$, pp. 702-3.

${ }^{147}$ Ver DUFF, "Inclusion, exclusion and the criminal law", cit. nota $\mathrm{n}^{\circ} 121$, pp. 705-7.

${ }^{148}$ DUFF, "Inclusion, exclusion and the criminal law", cit. nota $\mathrm{n}^{\circ} 121, \mathrm{p} .708$.

${ }^{149}$ Ver e.g. DUFF, R. A., Punishment, Communication and Community, Oxford: OUP, 2001, pp. 75-82.

${ }^{150}$ DUFF, Punishment, Communication, cit. nota $\mathrm{n}^{\circ} 149$, p. 75 (énfasis agregado).

${ }^{151}$ DUFF, Punishment, Communication, cit. nota $\mathrm{n}^{\circ} 149$, p. 77.

152 DUFF, R. A., Citizens, Enemies, Outlaws: The Criminal Law and Its Addressees (Paper presented at Hebrew University, 21 May 2008), p. 7.
} 
como miembros de una comunidad. ${ }^{153}$ Para hacer que un condenado asuma responsabilidad, en una forma muy similar a la de Bennett, Duff apunta a que el castigo tiene como finalidad reparar "nuestra relación cívica con nuestros conciudadanos: nos responsabiliza como ciudadanos cuya pertenencia en la sociedad no está en tela de juicio y esa es la razón por la cual el derecho a votar en prisión es simbólicamente importante.” 154

\subsection{Derecho democráticamente producido y castigo democrático}

Las dos concepciones de derecho penal descritas muestran interesantes conexiones entre la democracia y el castigo. Brettschneider se enfoca en la protección de derechos democráticos contra el poder punitivo del Estado. Duff, por su lado, muestra preocupación por la justificación comunitaria del castigo, sin embargo, su postura no desarrolla la importancia especifica de los derechos democráticos, enfocándose más bien en adoptar una concepción de democracia que se basa en las condiciones generales de la membresía en la comunidad. Ambos presentan una teoría del castigo democrático que está en conflicto con la práctica de la PDS. En un caso, porque afecta a los derechos democráticos sin justificación, constituyendo un uso arbitrario del poder punitivo; en el otro caso, porque desobedece la requerida inclusión para que el castigo sea legítimo en una comunidad democrática.

Es importante, sin embargo, destacar de manera específica la importancia del derecho a sufragio, dado que, en el contexto de democracia representativa, la importancia del derecho a sufragio es crucial. Pamela Karlan resume el argumento en los siguientes términos:

"La legitimidad del castigo criminal [...] depende de la legitimidad de los procesos políticos que producen e implementan la ley criminal. La legitimidad de ese proceso, a su vez, depende de la habilidad de los ciudadanos de participar igualmente en escoger a las autoridades que los representan al decidir qué conductas penalizar, qué individuos perseguir y cómo castigar a las personas involucradas en un delito."155

Una tercera teoría del castigo democrático, que permite abordar con claridad esta conexión, ha sido formulada por Kindhauser y Mañalich, quienes siguiendo a Habermas, articulan una conexión entre la producción democrática del derecho penal y la legitimidad del castigo. El castigo, según sostienen, sólo es legítimo en una democracia constitucional porque en ese contexto es posible entender a la persona, cuyo quebrantamiento intencional de una norma jurídica es considerado un delito, simultáneamente, como autor de la norma; y sólo en ese contexto es posible castigarlo legítimamente por un déficit objetivo de lealtad normativa. ${ }^{156}$ Esta es la premisa básica de una teoría del derecho penal democrático, de acuerdo a un

${ }^{153}$ DUFF, R. A., "Responsibility, citizenship, and criminal law", en: DUFF, R. A.; GREEN, S. (eds), Philosophical Foundations of Criminal Law, Oxford: OUP, 2011, pp. 125-148, p. 14. Ver también MAÑALICH, J. P., "Pena y ciudadanía", cit. nota n 138, pp. 135-138.

${ }^{154}$ DUFF, R. A., "Responsibility, citizenship, and criminal law", cit. nota $\mathrm{n}^{\circ} 153$, p. 15.

${ }^{155}$ KARLAN, "Ballots and bullets", cit. nota ${ }^{\circ} 28$, p. 1169. Ver también MANZA; UGGEN, Locked out, cit. nota $\mathrm{n}^{\circ}$ 2, p. 7; ZIEGLER, R., "The case for letting prisoners vote", UKHuman Rights Blog (2012).

${ }^{156}$ KINDHÄUSER, U.; MAÑALICH, J.P., Pena y Culpabilidad en el Estado democrático de Derecho, Buenos Aires: Editorial BdF, 2011, p. 1. 


\section{Polit. Crim. Vol. 15, № 28 (Diciembre 2019), Art. 15, pp. 520-561. [http://politcrim.com/wp-content/uploads/2019/12/Vol14N28A15.pdf]}

modelo de democracia en el que la legitimidad de la derecho está basada en la autonomía de los ciudadanos.

En este modelo, para ser compatible con la democracia, el castigo penal debe satisfacer ciertas condiciones. Estas condiciones no son sustancialmente diferentes de aquellas que cualquier otra imposición coactiva del derecho en una democracia debe satisfacer: el derecho penal democrático debe ser neutral y debe ser producido a través del proceso democrático. Neutralidad democrática implica que nadie puede ser castigado por seguir la ley, incluso cuando ha sido seguida por las razones equivocadas. El condenado no puede ser castigado porque su conducta fuera moralmente incorrecta, sino que sólo puede ser castigado si cometió un delito descrito en una norma legal. Además, el derecho penal debe ser consecuencia de un proceso democrático de producción, en el que las personas poseen derechos de participación, adoptando, por consiguiente, la calidad de ciudadanos. En el ejercicio de este rol, una persona puede asumir una posición crítica contra las normas legales y abogar por su modificación o derogación.

\subsubsection{Culpabilidad como déficit de lealtad democrática}

Los requisitos descritos anteriormente tienen implicancias fundamentales para la noción de culpabilidad penal y merecen por ello una atención detenida. La culpabilidad, para una concepción del derecho basada en la autonomía deliberativa de la persona, no implica la atribución positiva de responsabilidad por una conducta. Por el contrario, sólo se preocupa con determinar negativamente las condiciones bajo las cuales una atribución tal es descartada. Típicamente, las condiciones que excluyen la culpabilidad de la conducta de una persona son tres. Primero, la ausencia de capacidad cognitiva por parte del sujeto necesaria para entender las implicaciones legales de sus acciones; segundo, la falta de conocimiento del derecho que transforma las acciones de una persona en un delito (error iuris incluso cuando generalmente ignorantia iuris nocet), y tercero, la concurrencia de circunstancias que hacen el respeto de la ley una carga insoportable (excusas absolutorias). ${ }^{157}$

Las razones para la construcción negativa de culpabilidad son, primero, que la atribución de responsabilidad penal se encuentra inserta en un sistema legal que ya está basado en la concepción de la persona deliberativa. Derechos y responsabilidades son atribuidas por defecto, debido al reconocimiento general de la capacidad de las personas de evaluar críticamente normas y acciones. ${ }^{158}$ Las causas de exclusión de culpabilidad mencionadas más arriba son casos en que dicho poder deliberativo es deficiente, o bien, inexistente. ${ }^{159}$ En contraste, cuando estas causas no concurren, se puede concluir que una persona pudo

\footnotetext{
${ }^{157}$ Ver GÜNTHER, K., "Communicative freedom, communicative power, and jurigenesis", Cardoso Law Review, Vol. 17 (1996), pp. 1035-1058, 8-9. Ver también KINDHÄUSER, U., "Culpabilidad jurídico penal en el estado democrático de derecho", en: KINDHAUSER, U.; MAÑALICH, J.P., Pena y Culpabilidad en el Estado democrático de Derecho, Buenos Aires: Editorial BdF, 2011, pp. 211-231.

${ }^{158}$ Sobre la atribución de este reconocimiento, ver MARSHALL, P. "El derecho a sufragio de los menores de edad: el argumento de la capacidad política", Revista de Ciencia Política (Santiago), Vol. 37, No 1 (2017), pp. $1-24$, pp. 15 y ss.

${ }^{159}$ Ver KINDHÄUSER, “Culpabilidad jurídico penal”, cit. nota n 157, pp. 211-218.
} 
haber decidido actuar conforme al derecho, pero en su lugar, decidió actuar en su contra. ${ }^{160}$ Segundo, hay una expectativa normativa de conducta conforme al derecho que aplica a las personas que viven en una sociedad organizada democráticamente. Que aquellas personas que han quebrantado el derecho sean titulares de derechos de participación, hace esperar que su desacuerdo sea vertido dentro del proceso político. Esa conducta no puede contar como una expresión de desacuerdo legítimo, sino sólo como una deslealtad hacia un acuerdo alcanzado democráticamente. ${ }^{161} \mathrm{La}$ atribución del derecho a participar en el proceso de producción de ley es, por lo tanto, una precondición de la responsabilidad criminal en una sociedad democrática. ${ }^{162}$ Sin estos derechos, el castigo no puede ser impuesto como consecuencia de una deslealtad hacia el proceso democrático porque la norma infringida no podría ser vista como una norma propia del condenado. Esta es la razón por la que, en un modelo democrático de derecho penal, el castigo sólo puede ser impuesto a aquellos que son tratados como ciudadanos. Sin embargo, el hecho del delito no puede impedir que la norma infringida sigua siendo la norma del condenado y que el éste siga siendo un ciudadano. ${ }^{163}$ En suma, la condena involucrada en el castigo y las consecuencias que le siguen deben ser adaptadas al marco democrático.

\subsection{2. ¿Qué cuenta y qué no puede contar como castigo democrático?}

Los requerimientos de neutralidad y producción democrática de ley, y las condiciones negativas bajo las cuales se puede atribuir culpabilidad a una persona, implican la necesidad de establecer parámetros mínimos de acuerdo con los cuales la imposición de un castigo pueda ser compatible con la democracia. Dos casos, relacionados con los requerimientos antes mencionados, son particularmente claros. Primero, la criminalización de las conductas, que no pueden ser completamente determinadas desde antes de su realización, está prohibida bajo el principio de neutralidad. El sujeto debe ser capaz de planear racionalmente su conducta, de acuerdo a un conjunto de reglas que constriñan a la misma, de manera que pueda evitar ser castigado, adaptando sus actos al derecho. Los principios de lex praevia, stricta, scripta et certa desempeñan el rol fundamental para restringir el poder punitivo del Estado, en equilibrio con la necesidad de certeza y libertad individual. Segundo, la criminalización de las expresiones formales de disenso no puede ser justificada democráticamente. En una democracia, los ciudadanos deberían ser capaces de demostrar su desacuerdo; de lo contrario, se destruye la base del proceso democrático consistente en la posibilidad de la crítica política. ${ }^{164}$ Bajo este tipo de condiciones, el principio de neutralidad se ve erosionado, porque no es capaz de proteger las diferentes concepciones del 'bien' existentes en una sociedad pluralista. Criminalizar el disenso es un claro ejemplo de derecho penal antidemocrático.

\footnotetext{
${ }^{160}$ MAÑALICH, "Pena y ciudadanía", cit. nota n 138, p. 118.

${ }^{161}$ Ver KINDHÄUSER, U., "La fidelidad al derecho como categoría de la culpabilidad", KINDHAUSER, U.; MAÑALICH, J.P., Pena y Culpabilidad en el Estado democrático de Derecho, Buenos Aires: Editorial BdF, 2011, pp. 69-108, pp. 102-105. Ver también MAÑALICH, J. P., "Determinism, free will and criminal responsibility", en: TOEPEL, F. (ed.) Free will in criminal law and procedure: proceedings of the $23 \mathrm{rd}$ and 24th IVR World Congress Kraków 2007 and Beijing 2009, Ed. Nomos, 2010, pp. 49-61, pp. 59-61.

${ }^{162}$ Ver MAÑALICH, J. P., "Determinism", cit. nota n 161, p. 60.

${ }^{163}$ MAÑALICH, "Pena y ciudadanía", cit. nota n ${ }^{\circ} 138$, pp. 125 y ss.

${ }^{164}$ Ver e.g. PETTIT, P., "Democracy, electoral and contestatory", Nomos, Vol. 42 (2000), pp. 105-144, passim.
} 


\section{Polít. Crim. Vol. 15, № 28 (Diciembre 2019), Art. 15, pp. 520-561. [http://politcrim.com/wp-content/uploads/2019/12/Vol14N28A15.pdf]}

Sin embargo, no sólo un proceso de criminalización legal de una conducta puede estar en conflicto con la democracia. Las reglas de atribución de responsabilidad, y la regulación del castigo, también deben estar en concordancia con principios democráticos. Esto implica, haciendo referencia al primero de estos aspectos, que el castigo no puede ser impuesto a aquellos que no son reconocidos como capaces de seguir las normas legales. En este sentido, por ejemplo, la atribución de responsabilidad criminal a menores, está en tensión con la idea de culpabilidad democrática. Basándose en la atribución de un déficit de capacidad legal en otras áreas de la vida y, especialmente, en su exclusión del ejercicio de derechos políticos, está claro que la sociedad no espera un ejercicio del poder deliberativo por parte de los menores. La imposición de un castigo, por tanto, podría ser criticada. ${ }^{165}$

En relación al castigo, éste no puede estar dirigido a la instrumentalización del condenado. El único propósito del castigo que no está parece estar afectado por este problema es la retribución. Esto no significa decir, como ya se mencionó, que el castigo no puede, adicionalmente, alcanzar otros propósitos, como la disuasión; sino que estos otros propósitos no pueden asumir un rol primario en la imposición del castigo. La rehabilitación y la incapacitación, desde esta perspectiva, son especialmente problemáticas en relación al derecho penal democrático. La primera representa una imposición en la esfera de la autonomía del sujeto que es incompatible con el respeto a la misma. La segunda, por su lado, no considera al sujeto como un agente legal definido como autónomo, sino sólo como un peligro que debe ser prevenido.

Finalmente, llegando a cómo está concepción del castigo penal se relaciona con la PDS, la forma adoptada por la respuesta punitiva, debe ser consistente con los requerimientos del derecho penal democrático. El castigo no puede borrar la base sobre la cual radica la expectativa normativa de la conducta conforme a derecho de una persona. ${ }^{166} \mathrm{Si}$ lo que hace posible la condena de una conducta delictual (como un déficit de lealtad democrática) es la posibilidad de que el condenado, como ciudadano, pueda cuestionar la ley dentro del proceso político, entonces la denegación de sus derechos de participación democrática constituye la destrucción de la base misma sobre la cual el sujeto puede ser penalmente responsable. Este es el sentido específico en que la PDS está en tensión con la práctica de la responsabilidad criminal en una democracia. La pérdida de derechos de participación como consecuencia de una condena criminal explicita que la PDS no funciona como un castigo, sino que funciona como una práctica de degradación y exclusión.

\section{Conclusión}

Haciendo un resumen de las reflexiones centrales de este trabajo, se puede decir que la PDS no puede ser justificada como un castigo democrático, dado que no puede superar las objeciones que se le plantean en ese sentido. Esto es así porque no puede explicarse en

\footnotetext{
${ }^{165}$ Ver MARSHALL, "Disenfranchisement and political capacity", cit. nota 15, pp. XX. Este punto de vista es adoptado en Sauvé v Canada: "De hecho, el derecho del Estado a castigar y la obligación del condenado a aceptar el castigo penal están atados a la aceptación social de la calidad de persona del condenado, que incluye derechos y responsabilidades." (c. 47).

${ }^{166}$ Ver MAÑALICH, "Pena y ciudadanía”, cit. nota n 138, pp. 127-33.
} 
términos de incapacitación, rehabilitación o disuasión, y cuando se argumenta que puede desempeñar una función retributiva, se llega a la conclusión de que no hay razones como para preferirla por sobre otras formas de castigo. El más sofisticado argumento para justificar la necesidad de la privación del derecho a sufragio, que lo vindica como una forma óptima de castigo expresivo, termina siendo poco convincente y contraproducente dentro de su propio marco conceptual. Hay buenas razones para pensar, por el contrario, que la privación del derecho a sufragio es una forma de castigo impermisible en una democracia, porque priva de un derecho que parece fundamental a la hora de imponer un castigo a aquellos que cometen un delito.

El análisis crítico de la discusión desarrollada en el contexto de las jurisdicciones del common law que se ha llevado a cabo en este artículo podría servir para iluminar y fortalecer la incipiente discusión sobre este asunto en Latinoamérica ${ }^{167}$. Para ello, sin embargo, es necesario que los insumos teóricos y jurídicos que la discusión comparado ha producido sean puestos en relación, con la tradición teórica y jurídica de la tradición continental $^{168}$, vigente en Latinoamérica.

${ }^{167}$ Ver e.g. FILIPPINI, L.; ROSSI, F., "Nuevos aportes para el reconocimiento del derecho al voto de las personas condenadas", Revista Jurídica de la Universidad de Palermo, Año 13, Vol 1 (2012), pp. 187-213; RÍOS, L. E., "El canon europeo e interamericano de la privación del sufragio pasivo", Cuestiones Constitucionales, $\mathrm{N}^{\circ} 36$ (2017), pp. 109-141, passim.

168 Completas referencias, aunque un tanto desactualizadas, al tratamiento teórico y dogmático de esta cuestión en Alemania pueden encontrarse en DEMLEITNER, "Continuing payment", cit. nota n ${ }^{\circ}$, pp. 756765. 


\section{Bibliografía}

ALTMAN, A., "Democratic Self-Determination and the Disenfranchisement of Felons", Journal of Applied Philosophy, Vol. 22, No 3 (2005), pp. 263-273.

BECKMAN, L., The Frontiers of Democracy. The right to vote and its limits, London: Palgrave Macmillan, 2009.

BEHAN, C., "The benefit of personal experience and personal study: prisoners and the politics of enfranchisement", The Prison Journal, Vol. 91 (2011), pp. 7-31.

BEHAN, C., Citizen Convicts: Prisoners, Politics and the Vote, Manchester, Manchester University Press, 2014.

BEHRENS, A., "Note: Voting- Not quite a fundamental right? A look at legal and legislative challenges to felon disenfranchisement laws", Minnesota Law Review, Vol. 89 (2004), pp. 231-275.

BENNETT, C., The Apology Ritual, Cambridge: CUP, 2008.

BENNETT, C., "Penal disenfranchisement", Criminal law and philosophy, Vol. 10, N 3 (2016), pp. 411-425.

BENNETT, C.; VIEHOFF, D., "Prisoner voting for the final general election before release is a solution that balances concerns about democratic rights", Democratic Audit UK (2013).

BENNETT, S., "Giving Ex-Felons the Right to Vote", California Criminal Law Review, Vol. 1 (2003).

BOWERS, M.; PREUHS, R., "Collateral consequences of a collateral penalty: the negative effect of felon disenfranchisement laws on the political participation of nonfelons", Social Science Quarterly, Vol. 90, Nº 3 (2009), pp. 722-743.

BRENNER, S.; CASTE, N. J., "Granting the Suffrage to Felons in Prison", Journal of Social Philosophy, Vol. 34, No 2 (2003), pp. 228-243.

BRETTSCHNEIDER, C., Democratic Rights. The substance of self-government, Princeton: Princeton University Press, 2007.

BRETTSCHNEIDER, C., "The rights of the guilty", Political Theory, vol. 35 (2007), pp. 175-199.

BÜLLOW, W., "Felon disenfranchisement and the argument for democratic selfdetermination", Philosophia, Vol. 44 (2016), pp. 759-774.

CHOLBI, M., "A felon's right to vote", Law and Philosophy, Vol. 21, No 4/5 (2002), pp. 543-565.

CLEGG, R., "Who should vote?", Texas Review of Law and Politics, Vol. 6 (2002), pp. 159-178.

DAMASKA, M., "Adverse legal consequences of conviction and their removal: a comparative study (Part 1)", Journal of Criminal Law, Criminology and Police Science, Vol. 59, № 3 (1968), pp. 347-360.

DAVISON, J., "Inside outcast: prisoners and the right to vote in Australia", Information and Research Services Parliamentary Library, Vol. 12 (2004).

DE GREIFF, P., "Deliberative democracy and punishment", Buffalo Criminal Law Review Vol. 5, No 2 (2002), pp. 373-403. 
DEMLEITNER, N., "Continuing payment on one's debt to society: the German model of Felon disenfranchisement as an alternative", Minnesota Law Review, Vol. 84 (2000) 753-804.

DEMLEITNER, N., "U. S. felon disenfranchisement: parting ways with western Europe", en: EWALD A.; B. ROTTINGHAUS (eds.), Criminal disenfranchisement in an international perspective, Cambridge: Cambridge University Press, 2009, pp. 79108.

DHAMI, M., "Prisoner disenfranchisement policy: a threat to democracy?", Analysis of Social Issues and Public Policy, Vol. 5, No 1 (2005), pp. 235-247.

DUFF, R. A., Punishment, Communication and Community, Oxford: OUP, 2001.

DUFF, R. A., "Inclusion, exclusion and the criminal law", Policy Futures in Education, Vol. 1, No 4 (2003), pp. 699-715.

DUFF, R. A., "Introduction: crime and citizenship", Journal of Applied Philosophy, Vol. 22, No 3 (2005), pp. 211-216.

DUFF, R. A., Citizens, Enemies, Outlaws: The Criminal Law and Its Addressees (Paper presented at Hebrew University, 21 May 2008). Available online: http://law.huji.ac.il/eng/calendar.asp?act=event\&event_id=54\&cat=776\&thepage=ir uim [28.06.14]

DUFF, R. A., "Responsibility, citizenship, and criminal law", en: DUFF, R. A.; GREEN, S. (eds), Philosophical Foundations of Criminal Law, Oxford: OUP, 2011, pp. 125148.

EASTON, S., "Electing the electorate: the problem of prisoner disenfranchisement", Modern Law Review, Vol 69, № 3 (2006), pp. 443-461.

EASTON, S., "The prisoner's right to vote and civic responsibility: Reaffirming the social contract?", Probation Journal, Vol. 56 (2009), pp. 224-237.

EWALD, A., "Civil Death: The Ideological Paradox of Criminal Disenfranchisement Law in the United States", Wisconsin Law Review, Vol. 5 (2002), pp. 1045-1137.

EWALD, A., "An 'agenda for demolition': the fallacy and the danger of the 'subversive voting' argument for felony disenfranchisement", Columbia Human Rights Law Review, Vol. 36 (2004), pp. 109-143.

EWALD, A., "Mundos aparte: las leyes sobre suspensión del derecho a sufragio en las Cortes Supremas", II Seminario Internacional del Observarotio Judicial Electoral, November 2009, Mexico. Available online: http://www.te.gob.mx/ccje/Archivos/ponencias/alec_ewald.pdf [07/12/2012].

FEINBERG, J., "The expressive function of punishment", en: FEINBERG, J., Doing and Deserving. Princeton: Princeton University Press, 1970, pp. 95-117.

FILIPPINI, L.; ROSSI, F., "Nuevos aportes para el reconocimiento del derecho al voto de las personas condenadas", Revista Jurídica de la Universidad de Palermo, Año 13, Vol 1 (2012), pp. 187-213.

FLETCHER, G. P., Basic concepts of criminal law. New York: OUP, 1998.

FLETCHER, G. P., "Disenfranchisement as punishment: reflection on the racial uses of infamia", UCLA Law Review, Vol. 46 (1999), pp. 1895-1907.

GEDDIS, A., "Prisoner voting and rights deliberation: how New Zealand's Parliament failed", New Zealand Law Review (2011), pp. 443-474. 
GRADY, S., "Civil death is different: and examination of a post-Graham challenge to felon disenfranchisement under the eighth amendment", The Journal of Criminal Law and Criminology, Vol. 102, $\mathrm{N}^{\mathrm{o}} 2$ (2012), pp. 441-470.

GÜNTHER, K., "Communicative freedom, communicative power, and jurigenesis", Cardoso Law Review, Vol. 17 (1996), pp. 1035-1058.

HAMILTON-SMITH, G.; VOGEL, M., "The ballot as a bulwark: the impact of felony disenfranchisement on recidivism", 2011. Available online: http://ssrn.com/abstract=1919617 [20.10.2014].

HAMPTON, J., "An expressive theory of retribution", en: CRAGG, W. (ed), Retributivism and its Critics, Stuttgart: Franz Steiner Verlag, 1992.

HAMPTON, J., "Punishment, Feminism, and Political Identity: a case study in the expressive nature of law", Canadian Journal of Law and Jurisprudence Vol. 11, $\mathrm{N}^{\mathrm{o}}$ 1 (1998), pp. 23-45.

HILL, L.; KOCH, C., "The voting rights of incarcerated Australian citizens", Australian Journal of Political Science, Vol. 46, № 2 (2011), pp. 213-228.

HUGH M.; ROBERTS, J., "Written Evidence", en: Joint Committee on the draft Voting Eligibility (Prisoners) Bill Oral and Written Evidence, 2013. Available online: http://www.parliament.uk/documents/joint-committees/Draft-Voting-EligibilityPrisoners-Bill/prisonervoting-evidvol\%20(4).pdf [22.10.2014].

HUSAK, D., "The Criminal Law as Last Resort", Oxford Journal of Legal Studies, Vol. 24, $\mathrm{N}^{\mathrm{o}} 2$ (2004), pp. 207-235.

ISPAHANI, L., "Voting rights and human rights: a comparative analysis of criminal disenfranchisement laws", en: EWALD, A.; ROTTINGHAUS, B. (eds), Criminal disenfranchisement in an international perspective, New York: CUP, 2009, pp. 2558.

ITZKOWITZ, H.; OLDAK, L., "Note: Restoring the ex-offender's right to vote: background and developments", American Criminal Law Review, Vol 11 (1973), pp. 721-770.

JOHNSON-PARRIS, A. S., "Felon disenfranchisement: The unconscionable social contract breached", Virginia Law Review, Vol. 89, No 1 (2003), pp. 109-138.

JOINT COMMITTEE ON DRAFT VOTING ELIGIBILITY (PRISONERS) BILL, Report (2013, HL 103, HC 924). Available online: http://www.publications.parliament.uk/pa/jt201314/jtselect/jtdraftvoting/103/103.pd f [23.05.2014].

KARLAN, P., "Ballots and bullets: the exceptional history of the right to vote", University of Cincinnati Law Review, Vol. 71 (2003), pp. 1345-1372.

KINDHÄUSER, U., "La fidelidad al derecho como categoría de la culpabilidad", en: KINDHÄUSER, U.; MAÑALCH, J.P., Pena y Culpabilidad en el Estado democrático de Derecho, Buenos Aires: Editorial BdF, 2011, pp. 69-108.

KINDHÄUSER, U., "Culpabilidad jurídico penal en el estado democrático de derecho”, en: KINDHÄUSER, U.; MAÑALICH, J.P., Pena y Culpabilidad en el Estado democrático de Derecho, Buenos Aires: Editorial BdF, 2011, pp. 211-231.

KINDHÄUSER, U.; MAÑALICH, J.P., Pena y Culpabilidad en el Estado democrático de Derecho, Buenos Aires: Editorial BdF, 2011.

KLEINIG J.; MURTAGH, K., "Disenfranchising Felons", Journal of Applied Philosophy, Vol. 22 (2005), pp. 217-39. 
LACEY, N., "Denying prisoners the vote creates a barrier to their reintegration into society", Democratic Audit UK (2013).

LACEY, N., "Oral Evidence", en: Joint Committee on the draft Voting Eligibility (Prisoners) Bill Oral and Written Evidence, 2013. Available online: http://www.parliament.uk/documents/joint-committees/Draft-Voting-EligibilityPrisoners-Bill/prisonervoting-evidvol\%20(4).pdf [22.10.2014].

LARDY, H., "Prisoner disenfranchisement: constitutional rights and wrongs", Public Law, (2002), pp. 524-545.

LATIMER, S. B., "Can felon disenfranchisement survive under modern conceptions of voting rights? Political philosophy, state interests, and scholarly scorn", SMU Law Review Vol. 59 (2006), pp. 1841-1867.

LAVI, S., "Citizenship revocation as punishment: on the modern duties of citizens and their criminal breach", University of Toronto Law Journal, Vol. 61 (2011), pp. 783-810.

LEVINE, E. L., "Does the Social Contract Justify Felony Disenfranchisement?", Washington University Jurisprudence Review, Vol. 1 (2009), pp. 193-224.

LIPPKE, R., "The Disenfranchisement of Felons", Law and Philosophy, Vol. 20, № 6 (2001), pp. 553-580.

LÓPEZ-GUERRA, C., Democracy and Disenfranchisement: The Morality of Electoral Exclusions, New York: OUP, 2014

LOVE, M. C., "Collateral consequences after Padilla v Kentucky: from punishment to regulation”, Saint Louis University Public Law Review, Vol 31 (2011), pp. 87-128.

MAÑALICH, J. P., "Determinism, free will and criminal responsibility", TOEPEL, F. (ed.) Free will in criminal law and procedure: proceedings of the 23rd and 24th IVR World Congress Kraków 2007 and Beijing 2009, Ed. Nomos, 2010, pp. 49-61.

MAÑALICH, J. P., "Pena y ciudadanía”, en: KINDHÄUSER, U.; MAÑALICH, J.P., Pena y Culpabilidad en el Estado democrático de Derecho, Buenos Aires: Editorial BdF, 2011, pp. 116-142.

MAÑALICH, J. P., "El derecho penitenciario entre ciudadanía y los derechos humanos", Derecho y Humanidades, Vol. 18 (2011), pp. 163-178.

MANFREDI, C., "In Defence of Prisoner Disenfranchisement", en: EWALD, A.; ROTTINGHAUS, B. (eds), Criminal disenfranchisement in an international perspective, New York: CUP, 2009, pp. 259-280.

MANZA, J.; UGGEN, C., Locked out: Felon disenfranchisement and American democracy, New York: OUP, 2006.

MARSHALL, P., "Disenfranchisement and political capacity", en: GRIFFITHS, A.; MUSTASAARI, S.; MÄKI-PETAJÄ-LEINONEN, A. (eds.), Subjectivity, Citizenship and Belonging in Law: Identities and Intersections, London: Routledge, 2016, pp. 53-71.

MARSHALL, P., "Suspension of political rights of prisoners", en: GROTE; LACHENMANN; WOLFRUM (eds.), Max Planck Encyclopedia of Comparative Constitutional Law, Oxford: Oxford University Press, 2017.

MARSHALL, P. "El derecho a sufragio de los menores de edad: el argumento de la capacidad política", Revista de Ciencia Política (Santiago), Vol. 37, No 1 (2017), pp. 1-24.

MARSHALL, P., "Voting from prison: against the democratic case for disenfranchisement", Ethics and Global Politics, Vol. 11, pp. 1-16. 
MARSHALL, P., "El derecho a votar de los privados de libertad: propuestas para una reforma", en: CONTESSE, J.; CONTRERAS, M. I. (eds.), La insostenible situación de las cárceles en Chile: debate sobre la prisión y los Derechos Humanos, Santiago: Editorial Jurídica de Chile, 2019.

MARSHALL, P.; ROCHOW, D., "El voto de las personas privadas de libertad. Comentario de la sentencia Rol N ${ }^{\circ} 87743-2016$ de la Corte Suprema", Revista Chilena de Derecho, Vol. $45 \mathrm{~N}^{\mathrm{o}}$ 1, pp. 233-54.

MAUER, M., "Felon disenfranchisement: a policy whose time has passed?", Human Rights (American Bar Association), Vol. 31, Nº 1 (2004), pp. 16 y ss.

MILLER, B. L.; SPILLANE, J., "Civil death: an examination of ex-felon disenfranchisement and reintegration", Punishment \& Society Vol. 14, No 4 (2012), pp. 402-428.

MORRIS, C., "Punishment and the loss of moral standing", Canadian Journal of Philosophy, Vol. 21, No 1 (1991), pp. 53-80.

MUNN, N., "The limits of criminal disenfranchisement", Criminal Justice Ethics, Vol. 30, $\mathrm{N}^{\mathrm{o}} 3$ (2011), pp. 223-239.

NOTE, "The need of reform of ex-felons disenfranchisement laws", in Yale Law Journal, Vol. 83, No 3 (1974), pp. 580-601.

NOTE, "The Disenfranchisement of ex-felons: citizenship, criminality, and the purity of the ballot box"”, Harvard Law Review, Vol. 102 (1989), pp. 1300-1317.

ORR, G., "Ballotless and behind bars: the denial of the franchise to prisoners", Federal Law Review, Vol. 26 (1998), pp. 55-82.

ORR, G.; WILLIAMS, G., "The People's choice: the prisoners franchise and the constitutional protection of voting rights in Australia", Election Law Journal, Vol. 8, No 2 (2009), pp. 123-139.

POAMA, A.; THEUS, T., "Making offenders vote: democratic expressivism and coerced criminal voting", presentación en Seminario The Politic and Ethics of Disenfranchisement, Universidad de Manchester, 2017.

PETTIT, P., "Democracy, electoral and contestatory", Nomos, Vol. 42 (2000), pp. 105-144.

PLANINC, Z., "Should imprisoned criminals have a constitutional right to vote?", Canadian Journal of Law and Society, Vol. 2 (1987), pp. 153-164.

PLAXTON, M.; LARDY, H. "Prisoner Disenfranchisement: Four Judicial Approaches", Berkeley Journal of International Law, Vol. 28, No 1 (2010), pp. 101-141.

RAMSAY, P., "Faking democracy with prisoners' voting rights", LSE Law, Society and Economy Working Papers 7/2013.

RAMSAY, P., "Voters should not be in prison! The rights of prisoners in a democracy", Critical Review of International Social and Political Philosophy, Vol. 16, № 3 (2013b), pp. 421-438.

RE, R.; RE, C., "Voting and vice: criminal disenfranchisement and the reconstruction amendments", Yale Law Journal, Vol. 121 (2012), pp. 1584-1670.

REBACK, G. L., "Disenfranchisement of Ex-Felons: A Reassessment", Stanford Law Review, Vol. 25, № 6 (1973), pp. 845-864.

REIMAN, J., "Liberal and republican arguments against the disenfranchisement of felons", Criminal Justice Ethics, winter/spring 2005, pp. 3-18.

RÍOS, L. E., "El canon europeo e interamericano de la privación del sufragio pasivo", Cuestiones Constitucionales, No 36 (2017), pp. 109-141. 
ROTHCHILD, J., "Dispenser of the mercy of the government: pardons, justice, and felony disenfranchisement", Journal of Religious Ethics, Vol. 39, № 1 (2011), pp. 48-70.

SCHALL, J., "The consistency of felon disenfranchisement with citizenship theory", Harvard Blackletter Law Journal, Vol. 22 (2006), pp. 53-93.

SIGLER, M., "Defensible disenfranchisement", Iowa Law Review, Vol. 49 (2013), pp. 1725-1744.

THOMPSON, M., "Don't do the crime if you ever intend to vote again: challenging the disenfranchisement of ex-felons as cruel and unusual punishment", Seton Hall Law Review, Vol. 33 (2002), pp. 168-205.

TIMS, D., "The disenfranchisement of ex-felons: a cruelly excessive punishment", Southwestern University Law Review, Vol. 7 (1975), pp. 125-160.

TRIPKOVIC, M., "The Modern Cives Sine Suffraggio: Dimensions of Criminal Disenfranchisement in Europe", The Howard Journal of Crime and Justice, Vol. 55 (2016), pp. 4-24.

VAN ZYL SMIT, D.; SNACKEN, S., Principles of European Prison Law and Policy, Oxford: OUP, 2009.

VILE, J., "Right to Vote as Applied to Ex-Felons", Federal Probation, Vol. 45 (1981), pp. 12-17.

VON HIRSCH, A., "Punishment, Penance, and the State", en: MATRAVERS, M. (ed), Punishment and Political Theory, Oxford: Hart, 1999.

VON HIRSCH, A.; ASHWORTH, A., Principled Sentencing, Edinburgh: Edinburgh University Press, 1992.

VON HIRSCH, A., WASIK, M., "Civil disqualifications attending conviction: a suggested conceptual framework", Cambridge Law Journal, Vol. 56, № 3 (1997), pp. 599626.

WALDRON, J., “Lex talionis”, Arizona Law Review, Vol. 34 (1992), pp. 25-51.

WALDRON, J., "Oral Evidence", en: Joint Committee on the draft Voting Eligibility (Prisoners) Bill Oral and Written Evidence, 2013. Available online: http://www.parliament.uk/documents/joint-committees/Draft-Voting-EligibilityPrisoners-Bill/prisonervoting-evidvol\%20(4).pdf [22.10.2014].

WILKINS, P. A., "The mark of Cain: disenfranchised felons and the constitutional no man's land", Syracuse Law Review, Vol. 56 (2005), pp. 85-144.

WHITMAN, J. Q., Harsh Justice. Criminal punishment and the widening divide between America and Europe, New York: OUP, 2003.

WHITT, M.S., Felon Disenfranchisement and Democratic Legitimacy, Social Theory and Practice, Vol. 43, pp. 283-311.

ZIEGLER, R., "Legal outlier, again? U. S. felon suffrage: comparative and international human rights perspectives", Boston University International Law Journal, Vol. 29 (2011), pp. 197-266.

ZIEGLER, R., "The case for letting prisoners vote", UKHuman Rights Blog (2012) Available online: http://ukhumanrightsblog.com/2012/05/24/the-case-for-lettingprisoners-vote-reuven-ziegler/ [22.08.13]. 


\section{Fallos judiciales}

Chan Kin Sum v Secretary for Justice [2009] 2 HKLRD 166 and [2008] 6 HKC 486. (08.12.2008, High Court of Hong Kong) Available online: http://www.cmab.gov.hk/doc/HCAL000079_2008.pdf

Minister of Home Affairs $v$ National Institute for Crime Prevention and the Re-Integration of Offenders (NICRO) and Others (CCT 03/04) [2004] ZACC 10 (03.03.2004, South African Constitutional Court). Available online: http://www.saflii.org/za/cases/ZACC/2004/10.html

Sauvé v Canada (Chief Electoral Officer), [2002] 3 S.C.R 519 (Sauvé No. 2) (31.10.2002, Supreme Court of Canada). Available online: http://scc.lexum.org/en/2002/2002scc68/2002scc68.html

$R$. (on the application of Chester) v Secretary of State for Justice and McGeoch $v$ The Lord President of the Council (2013) UKSC 63 (16.10.2013, Supreme Court of the United Kingdom). Available online: http://www.supremecourt.uk/decided-cases/docs/UKSC_2012_0151_Judgment.pdf

Richardson v Ramirez, 418 U.S. 24 (1974). (24.06.1974, Supreme Court of the United States of America). Available online: http://caselaw.lp.findlaw.com/scripts/getcase.pl?court=US\&vol=418\&invol=24

Hirst $v$ The United Kingdom (No. 2) [2005] ECHR 681. (06.10.2005, Gran Chamber of the European Court of Human Rights). Available online: http://hudoc.echr.coe.int/sites/eng/pages/search.aspx?i=001-70442

Roach v Commonwealth [2007] HCA 43 (26/09/2007, High Court of Australia). Available online: http://www.austlii.edu.au/au/cases/cth/HCA/2007/43.html

Scoppola v Italy (No. 3) [2012] ECHR 868. (22.05.2012, Gran Chamber of the European Court of Human Rights). Available online: http://hudoc.echr.coe.int/sites/eng/pages/search.aspx?i=001-111044 